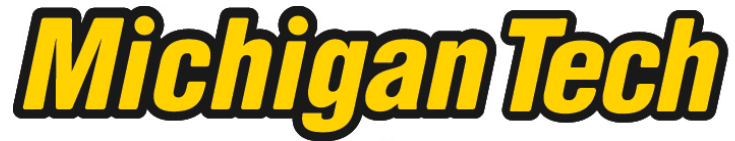 \\ Michigan Technological University Create the Future Digital Commons @ Michigan Tech
}

Dissertations, Master's Theses and Master's Reports - Open

Dissertations, Master's Theses and Master's

Reports

2015

STRUCTURE AND AGENCY IN ORGANIZATIONAL CONTEXTS OF WOMEN IN STEM

Sidouane Patcha Lum

Michigan Technological University

Follow this and additional works at: https://digitalcommons.mtu.edu/etds

Part of the Feminist, Gender, and Sexuality Studies Commons Copyright 2015 Sidouane Patcha Lum

\section{Recommended Citation}

Patcha Lum, Sidouane, "STRUCTURE AND AGENCY IN ORGANIZATIONAL CONTEXTS OF WOMEN IN STEM", Master's Thesis, Michigan Technological University, 2015.

https://doi.org/10.37099/mtu.dc.etds/958

Follow this and additional works at: https://digitalcommons.mtu.edu/etds

8 Part of the Feminist, Gender, and Sexuality Studies Commons 


\title{
STRUCTURE AND AGENCY IN ORGANIZATIONAL CONTEXTS OF WOMEN IN STEM
}

\author{
By \\ Sidouane Patcha Lum
}

\begin{abstract}
A THESIS
Submitted in partial fulfillment of the requirements for the degree of MASTER OF SCIENCE

In Rhetoric and Technical Communication
\end{abstract}

MICHIGAN TECHNOLOGICAL UNIVERSITY

2015

(C)2015 Sidouane Patcha Lum 
This thesis has been approved in partial fulfillment of the requirements for the Degree of MASTER OF SCIENCE in Rhetoric and Technical Communication.

Department of Humanities

\author{
Thesis Advisor: $\quad$ Dr. M. Ann Brady \\ Committee Member: Dr. Patricia Sotirin \\ Committee Member: Dr. Robert Johnson \\ Committee Member: Dr. Sarah Green
}

Department Chair: Dr. Ronald Strickland 
To my parents

With Love and Gratitude 


\section{TABLE OF CONTENTS}

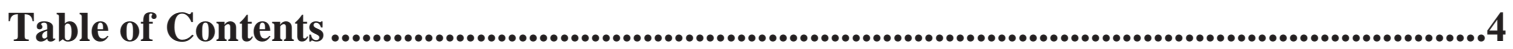

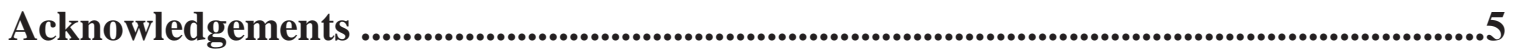

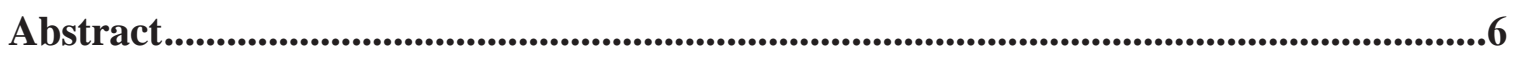

Outline of Chapters...........................................................................................................7

Chapter One:

Introduction and Background to STEM structures ..........................................9

Chapter Two:

Literature Review and Theoretical Framework ...........................................14

\section{Chapter Three:}

Methods: When Literature and Theory Intersect

Chapter Four:

Data Analysis: Making Meaning of Shared Experiences

Chapter Five:

Discussion and Conclusion: Rethinking STEM structures ......................................62

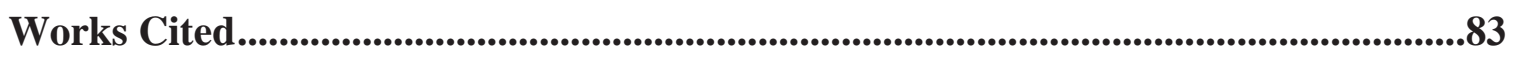

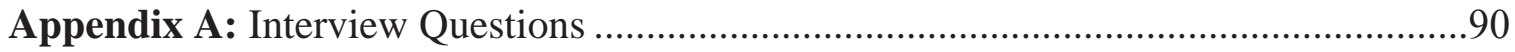

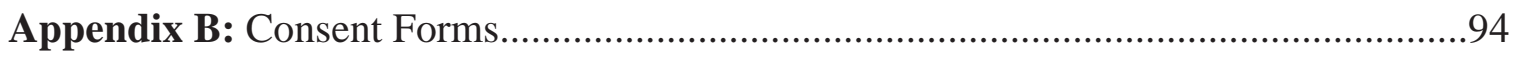

Appendix C: Participants Bibliographical Sketches...............................................100

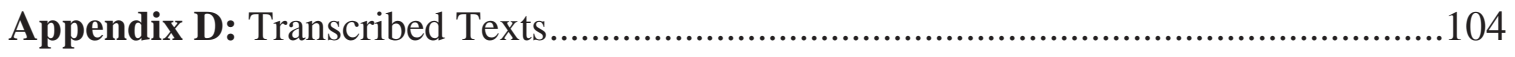




\section{Acknowledgements}

My gratitude to God for His immense blessings and guidance throughout my academic work. I am also very grateful for the support, encouragement and close supervision of my supervisor, Dr.Ann Brady. Thank you for being such a wonderful teacher and supervisor. My special appreciation also goes to my committee members Dr. Patricia Sotirin, Humanities; Dr. Robert Johnson, Humanities; and Dr. Sarah Green, Chemistry, for their invaluable contributions which made this work successful. I am also thankful to Dr. Vicky Bergvall, Humanities, for her assistance.

I acknowledge my interviewees for their dedication, cooperation and contributions to this research, which would not have been possible without them. Special thanks to my family, friends and colleagues who also supported me on this thesis. Sincerely... I remain grateful! 


\begin{abstract}
This research explores the extant literature on socio-cultural and institutional structures in STEM which accounts for women's under-representation in these fields. It questions eight women in STEM's awareness of these structures via interview sessions, and examines how they 'negotiate' their identities to thrive in 'male-dominated' fields. Participants' awareness and shared experiences of these structures reflects an evolving society still ingrained in gender stereotypes that work to the detriment of women in STEM. In order to make meaning out this data, I apply standpoint theory to get into these women's lives and explore the testable conclusions of traditional assumptions related to women in STEM. I close the gap between theory and empirical research by using grounded theory patterns of coding, categorizing and grouping of participant's responses to analyze the research situation. Major insights to this research lean on the importance of my interview participants' personal narratives (story-telling), out of which emerged the 'fifth- wheel' and 'headwind' metaphors. I present these metaphors as better alternatives to the 'leakypipeline metaphor' and contend that they offer new ways of thinking about how women in STEM 'negotiate' STEM structures and to what extent they are able to do so. It 'liberates knowledge' on how their successes can be maintained and how their challenges can be understood better.
\end{abstract}




\section{Outline of Chapters}

\section{Chapter One: Introduction and background to STEM structures}

In this chapter, I offer a rationale for my point of inquiry and take a critical look at agency and structure in the academic and professional context of women in STEM. I focus on the way these women negotiate and maintain their identities in a 'male centered' field.

\section{Chapter Two: Literature Review and Theoretical Framework}

This chapter provides a historical background for this research and proposes feminist standpoint theory as the theoretical framework guiding this research. I present some scholarly arguments on the issues which women face in STEM and suggest the relevance of these theory to the research.

\section{Chapter Three: Grounded Theory Research Method}

Here, I provide information about grounded theory and show its significance to my research. I go on to offer the different criteria used for selecting the interview participants in this research and also provide an account of the interview process. This includes: details on the total number of participants, venue, duration and mode of collecting data.

\section{Chapter Four: Data Analysis}

Data retrieved from field interviews is presented in this section. Steps of analyzing data using grounded theory as method would be indicated here. I identify initial, focused and in-vivo codes as well as categories and patterns which detail the research findings. 


\section{Chapter Five: Rethinking STEM Structures: Discussion and Conclusion.}

This section offers a discussion of the data analysis in comparison with the literature. It also reflects the significance and relevance of the theoretical framework to this research. On a broader note, it reveals the importance of this research by acknowledging these female participants standpoints as contributions to a general research on women. To conclude, I re-iterate the purpose of this work and highlight the research findings which are relevant in stimulating a better working atmosphere for women in STEM. I suggest ways through which this can be done and suggest spaces for further research. 


\section{Chapter 1 Introduction and background to STEM structures}

Differential gendered outcomes in the real world result from differences in resources attributable to choices, whether free or constrained...such choices could be influenced and better informed through education if resources were so directed (Ceci et al. 2011, pg.3157)

A broad outlook on the advancement of women in both academic and non-academic fields reveals a relatively slower pace than that of men. In academia, fields like philosophy, engineering and math have recorded a lower percentage of women over the years. The ratio of women to men in these non-academic career pathways have also been low over the years. However, the under-representation of women in Science, Technology, Engineering and Math (STEM), has received a lot of attention by contemporary scholars because several countries are faced with the challenge of recruiting and retaining women in STEM (Ong et al., 2011). It should be noted that this is not the case with all STEM fields given that some studies have reflected the over-representation of women in psychology, environmental, biological and medical sciences (George-Jackson, 2001). Jackson however adds that if we are to consider only the 'high-status, high profiles fields' in the domains of mathematics, engineering, computer and physical sciences, women still represent only $30 \%$ of undergraduate students. The National Science Board (2010) also indicates that in 2007, the female population made up for only 19\% of bachelor's degrees in computer sciences, $19 \%$ in engineering and $21 \%$ in physics; as at 2009, $12 \%$ of math and engineering bachelor's degrees were awarded to women in the United States. This low representation of women 
in STEM disciplines explains why less than $25 \%$ of women in 2011 had jobs in STEM related workplaces (Beede et al., 2011).

When compared to the $20^{\text {th }}$ century, the minimal presence of women in STEM has increased although it is not very glaring (NSF, Science \& Engineering Indicators, 2014). As at 2014, women make up for $39 \%$ of chemists and material scientists, $27.9 \%$ of environmental scientists and geoscientists, $15.6 \%$ of chemical engineers, $12.1 \%$ of civil engineers , $8.3 \%$ of electrical and electronics engineers, $17.2 \%$ of industrial engineers and 7.2\% of mechanical engineers (U.S. Department of Labor, Bureau of Labor Statistics, Women in the Labor Force: A Databook, 2014). It therefore becomes evident, as Leetaru (2010) argues, that although the gender gap between men and women has reduced, women are still lagging behind in STEM fields.

Considering that scientific and technological advancements are very important in sustaining and maintaining a highly industrialized and global world, encouraging women's participation in STEM fields has received much attention from many countries (Sonnert et al., 2007). However, for this to be effective researchers have taken up the task of tracing the root of female under-representation in STEM. Several possible reasons, such as differences in girls' and boys' attitudes towards science in the early secondary school years and lack of female interest, have been given as explanations for this gap. There are also arguments that the institutional culture of some STEM fields as well as the manner of teaching hinders female students from identifying with the field (Leetaru, 2010).

Limited space for student-teacher collaboration and co-operation among the students are also contributory factors to this (Cantor, 2010). To resolve this, measures have been taken to improve teaching and learning practices that will positively impact student's 
performance and subsequent retention in STEM (Frehiwot \& Dotger, 2014). As statistics imply, even these measures have not been very helpful in driving female numbers to STEM; by implication, these and other structural barriers affect students retention in these fields. Structure in this light is a combination of political, social, institutional and cultural patterns of arrangement, which has the potential to enhance or limit individual choices and opportunities (Barker, 2005). It is an important tool in social scientific discourse which helps in identifying complicated fragments of societal realities (Sewell, 1992).

Some of these structural barriers, according to Leetaru (2010), comprise of competitive attitudes in the classroom, shunning of women's interest, socialization of gender roles; and the 'masculinity' of engineering culture in STEM disciplines. At a higher level, discrimination in promotion, salary and grant funding also accounts for this (Cantor, 2010). Women's negative experiences via an encounter with these structures has created an unwelcoming climate for their accommodation in STEM fields. In trying to handle these stereotypes they face an even greater burden of a dampened self-confidence which affects their academic and career aspirations (Richman, 2011). Poggio (2006) suggests that "gender identities are constructed through a positioning process in which 'male and female are perceived and positioned as alternative categories" (p.228). The 'few' women present in STEM academic disciplines and related workplaces stand the chance of being 'politicized' bodies. Such a concern is in line with Wendt's argument that "the female body is made political when it is not equally incorporated or constituted like the male body; women are redefined in the male image and made political symbols of male dominance" (p.277). Marginalizations like this also highlight the argument that "masculinity and power are intertwined in such a way that men represent the standard: they naturally occupy the 
norm against which women's performance is measured. In other words, the attributes stereo-typically labelled as masculine...technical, physically strong and goal oriented, are valued higher and taken as the natural norm." (Brinke \& Stobbe 2009, p.4).

\section{Negotiating STEM pathways}

It would be limiting to say that structure alone contributes to all these gender issues in STEM fields. The ability for individuals to act as free agents, with the ability to make their own choices in a way that is not dictated by these social structures (Barker, 2005), is what I will refer to as agency. To have agency in this sense would be to suggest that women can negotiate the influence of political, social, cultural and institutional structures put in place by the STEM culture. Negotiation in the context of this research suggests ways through which women address the structures in STEM to be successful in their academic and STEM career. My point of inquiry stretches into the 'pipeline' model which looks at how women are sustained in STEM fields upon their decision to identify with STEM pathways (Richman, 2011).

In understanding how these women negotiate STEM structures to maintain their academic pathways, I also peep into the 'leaky pipeline' metaphor which has been coined to describe the different stages through which women drop out of their STEM education and careers. Gaining insight to the strategies employed by these women to remain in the 'pipeline' highlights ways through which the under-representation of women in STEM could also be curbed. Hence, I contend that the reduction of women at different stages of academia referred to as 'leaks' (Van Anders, 2004) could be controlled via means 
of negotiation. In studying these means of negotiation, I listen to women's stories and also examine other metaphors which emerge out of them.

This research therefore focuses on the standpoints of eight women in different STEM disciplines to observe how they have been able to negotiate, maintain and represent their identities in professional and academic contexts. More specifically I seek to find out to what extent these women are able to negotiate the predominant structures in STEM as a 'male centered' field.

The insights of this research are not applicable to all women in STEM fields, but rather stand to compliment a generalized research on women's experiences of STEM structures. It also serves as a beginning of looking at further questions in this regard. As such, I explore the following questions:

- How do women 'negotiate' STEM structures?

- To what extent are they able to do this?

This research exposes the challenges and successes which women in STEM face; it hopes to understand how their successes can be maintained and how the challenges can be understood better. The insights of these findings would be beneficial to incoming or aspiring females in the STEM field and to women at large. Moreover, they will also be a useful asset to the STEM field in enhancing a continuous re-rereading and re-writing of a history that includes women's voices in contemporary organizational and scientific academic discourse. 


\section{Chapter 2 \\ Literature Review and Theoretical Framework}

\section{Section A: Re-visiting Literature}

Programs that focus on increasing the number of women in science and engineering careers have not generally addressed a broader set of circumstances that intersect with gender at various economic levels and stages of life (Cozzens 2008, pg.346).

STEM Structures in the $20^{\text {th }}$ Century

An overview of the evolution of women in STEM over the years makes it apparent that there is a low percentage of female enrollment in STEM. Studies of these low representations in the $20^{\text {th }}$ century are propelled by scholars like Schiebinger and Londa (1999) who justified it with reasons like sexual discrimination against women and the challenge to balance work and family. Others argued that women were less privileged during work interviews or evaluations than men (Steinpreis et al., 1999a). It became more alarming as such implicit biases were suggested to be practiced by both men and women. Steinpreis et al. (1999) echo this with the argument that men and women are more willing to vote to hire a man than a woman based on an identical curriculum vitae.

The implicit biases of this structure also extended to unequal salaries between men and women. As Valian (1998) argued, “female graduates start out on equal salary footing with males but lose that equality as early as three to eight years post $\mathrm{Ph} . \mathrm{D} \ldots$ this salary discrepancies between men and women in science and engineering are greater than they are in the humanities"(p.225). In this light, Harding (1991) reiterated Rossiter (1982), that “all the formal barriers to women's equity in education, credentialing, lab appointments, research grants, and teaching positions have been eliminated, yet there are still few women 
to be found as directors and designers of research enterprises in the natural sciences"(p.22).

These and several other arguments on women's underrepresentation in STEM have been suggested and refuted over time by research scholars. The table below shows some of the myths and evidences given to disprove them.

Table 1: Myths about Women in STEM and Evidence Refuting Them

\begin{tabular}{|l|l|}
\hline Myth $\begin{array}{l}\text { Women lack the ability and drive to succeed } \\
\text { in STEM. }\end{array}$ & $\begin{array}{l}\text { Evidence } \\
\text { The structure and function of the brain, with } \\
\text { variances in cognitive development and } \\
\text { hormones in several studies have not proven } \\
\text { major significant differences in men's and } \\
\text { women's ability to excel in STEM. (Ceci \& } \\
\text { Williams, 2007). }\end{array}$ \\
In the United States, male and female \\
students perform at equal levels. (NAS, \\
2007). \\
Academia is a 'meritocracy'. \\
$\begin{array}{ll}\text { When considering the top 1 percent of both } \\
\text { male and female's mathematical abilities, } \\
\text { abilities, male adolescents are more likely to } \\
\text { obtain relatively more degrees in physical } \\
\text { sciences. The lack of 'innate' mathematics } \\
\text { ability has not been enough to account for } \\
\text { this difference. (Weinberger, 2005). }\end{array}$ \\
\hline be naturally be adjusted over time. \\
$\begin{array}{l}\text { The under- representation of women in } \\
\text { academic careers In the United States also } \\
\text { extends to fields with huge proportions of } \\
\text { female Ph.Ds., spanning for a period of 30 } \\
\text { years (NAS, 2007). }\end{array}$ \\
\hline $\begin{array}{l}\text { Scientists' decision to 'choose the best' } \\
\text { doesn't always usually depend on 'objective } \\
\text { criteria' but is also influenced by STEM } \\
\text { structures. These include: cultural biases, } \\
\text { race, age, sex, university location and other } \\
\text { factors not directly related to ability or } \\
\text { 'objective criteria'. }\end{array}$ \\
\hline
\end{tabular}




\begin{tabular}{|c|c|}
\hline & $\begin{array}{l}\text { - An article receives less favorable reviews } \\
\text { when it is identified as written by a female } \\
\text { author (Paludi \& Bauer, 1983). }\end{array}$ \\
\hline $\begin{array}{l}\text { There will be an adverse effect on education } \\
\text { standards of excellence if selection rules are } \\
\text { changed to promote gender equality. }\end{array}$ & $\begin{array}{l}\text { Advancement in STEM careers depend on a } \\
\text { performance assessment, usually by those } \\
\text { more advanced in the field. The presence of } \\
\text { biases and disproportionate considerations } \\
\text { of male qualities during this assessment } \\
\text { doesn't always enable a fair selection. } \\
\text { Reducing such bias will yield excellent results } \\
\text { in science and engineering fields. } \\
\text { Wenneras and Wold (1997) state that "a } \\
\text { woman has to be more than twice as } \\
\text { productive as a man to be judged equally } \\
\text { competent." }\end{array}$ \\
\hline $\begin{array}{l}\text { Female faculty members are not as } \\
\text { productive as their male counterparts. }\end{array}$ & $\begin{array}{l}\text { Over the last 30years, women in science have } \\
\text { been productive in publishing books and } \\
\text { articles at comparative rates with men. } \\
\text { Hindrances like children and parental care } \\
\text { responsibilities, marriage and the availability } \\
\text { of institutional resources have rather little } \\
\text { effects. } \\
\text { - According to Sedeño (ed.) (2001), "women } \\
\text { are members of low power committees, have } \\
\text { fewer financial resources, less support from } \\
\text { staff, or are located in offices which are } \\
\text { further away, lack access to "beginners' } \\
\text { networks" in order to obtain information, } \\
\text { and do not have models or mentors to ask } \\
\text { for advice or support." } \\
\text { Symonds (2007) finds that funding still } \\
\text { depends on the number of papers published, } \\
\text { which keeps men at the top. }\end{array}$ \\
\hline $\begin{array}{l}\text { Women are do not like to have jobs in } \\
\text { Academia. They are not as incompetent as } \\
\text { men. }\end{array}$ & $\begin{array}{l}\text { Both women and men in STEM intend to } \\
\text { continue with postdoctoral education or } \\
\text { related careers. }\end{array}$ \\
\hline $\begin{array}{l}\text { Women tend to prefer taking care of family, } \\
\text { than nurturing their careers. }\end{array}$ & $\begin{array}{l}\text { Women scientists manage their academic } \\
\text { careers regardless of its clashes with their }\end{array}$ \\
\hline
\end{tabular}




\begin{tabular}{|l|l|}
\hline & $\begin{array}{l}\text { roles as parents. Often times, their efforts, } \\
\text { contributions and dedication their careers } \\
\text { are not presented. }\end{array}$ \\
\hline $\begin{array}{l}\text { Women do not contribute much to the field } \\
\text { because they always take time off to attend } \\
\text { to parental duties. }\end{array}$ & $\begin{array}{l}\text { More women take maternity leave during } \\
\text { their early-careers. On average, in mid- } \\
\text { careers, men are more likely to take sick } \\
\text { leave. }\end{array}$ \\
\hline $\begin{array}{l}\text { Great scientists have already been produced } \\
\text { with the current system. No need to change it }\end{array}$ & $\begin{array}{l}\text { The nation is not benefiting from the } \\
\text { innovative perspectives of both men and } \\
\text { women due to cultural, sexist and other } \\
\text { forms of bias. }\end{array}$ \\
\hline
\end{tabular}

Source: Extracted and adapted from NAS (2007)

In order to effect changes that will benefit women, as feminist empiricists suggested, it remained important to examine and critically analyze some of these structures that hindered women from having agency. Based on the different means through which these structures operate, eliminating them suggested Harding (1991) would require a redefinition of objectivity, rationality and scientific method.

\section{STEM Structures in the $21^{\text {st }}$ Century}

In the $21^{\text {st }}$ century, scholars like Ecklund (2012) also suggest that both implicit biases and the structure of STEM discourage women from getting into the field. This is seen where 27 percent of computer and math working populations which comprised of women in 2009, decreased by three percent since 2000 (Beede et al, 2011). Additionals are that men and women in STEM have varying research opportunities and networks which often times favor the men Fox (2001). Ecklund and Lincoln (2011) also explore the notion that sociological factors account for the low representation of women in STEM. They argue 
that the 'nature of scientific' work has a profound effect on both men and women's family decisions and choices. The effect of this 'nature of scientific work', as expressed by some women, promotes a feeling of isolation amongst those of them who telecommute and work on computer models, coupled with their minimal representation, and limited time for a ‘meaningful work-life balance' (Mavriplis et al. 2010).

Hence the possibility of maintaining a balance between family and work is argued to have more impact on women's career choices. (Mason \& Ekman, 2007). It is on this note that married female scientists are said to interact with others to a lesser extent than men because of lack of time (Zuckerman, Cole \& Bruer, 1991). Despite the numerous attempts to maintain a gender balance in STEM, it is still regarded in academic discourse as a 'male-centered field'. The figure below represents a cross-section of these arguments in both the $19^{\text {th }}$ and $20^{\text {th }}$ centuries. It highlights a slice of the 'leaky-pipeline' problem by showing how women are under-represented in STEM. Although over 50\% of women have bachelor's degrees, only Biology is recorded to have maintained over 50\% of this population. Female enrollment in chemistry was a little over 50\% in 2005 but has now been gradually reducing. Women have for a long time, been under-represented in the other fields like Math and Statistics, Earth Sciences, Engineering and Physics. As the leaky pipeline suggests, the rather slow pace of female enrollment in these fields is because 'the volumetric flow rate' at the entry level is different from that at the exit level. This implies that the number of women who get into STEM are not directly equivalent to those who get out of STEM because some of them drop out. Hence I use this diagram to represent the 
slow pace of female enrollment and also to highlight this underrepresentation as a possibility that women drop out of STEM fields at different levels.

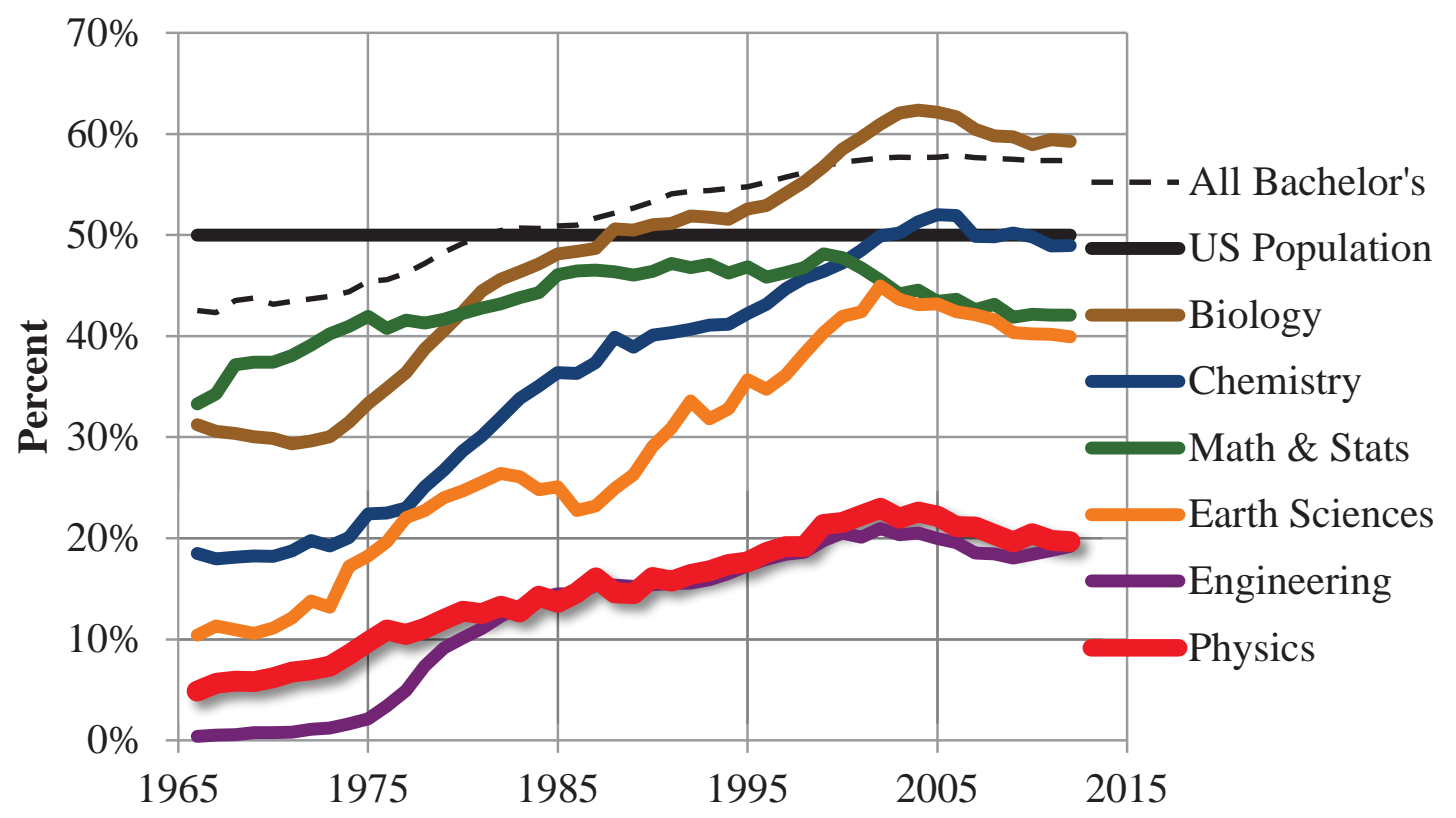

Figure 1: Percentage of Bachelor's degrees earned by Women in Different Majors

(C) 2014, American Physical Society

It still therefore holds that "sciences have been hostile to women in some periods and welcoming in others, and these shifts have had as much to do with patterns in the development of individual sciences as they have with the changing fortunes of sexism and androcentrism" (Harding 1991, p.22). 
These patterns of development are what I have referred to as structures in STEM which hinder women from having agency. Living in this patriarchal culture, according to Wendt (1995), causes women workers to "embody a feminine ideal but not to use their sexuality as a counterforce to efficiency and productivity" (p.276). He further intimates that "forced to fluctuate between a preordained difference (sexual stereotype) and similitude (a type of androgyny), they are caught in the powerlessness of contradictory action" (p.276). As Ferguson (1984) points out: "Women are not powerless because they are feminine; rather, they are feminine because they are powerless, because it is a way of dealing with the requirements of subordination" (p. 95). In other words, it appears that such stereotypes still exist and statistics indicate that women are still underrepresented. As such, my project seeks to examine this and answer how female participants in this research, if exposed to any of these structures in their individual STEM disciplines, have successfully negotiated them. 


\section{Section B: Theoretical Framework}

"Feminist research uses both women's own 'different' experience as its point of departure and processes this experience in a manner which leads to liberating knowledge" (Lundgren 1995, p. 25).

\section{Overview}

In this section, I discuss Feminist Standpoint Theory as the theoretical frame guiding this research on women's experiences in STEM. By shedding light on what these women value, reject or do not appreciate, I 'liberate knowledge' on the existence of structures in STEM, which when understood and interpreted, will help to maintain what women in STEM appreciate and improve their gender relations and experiences in areas where they struggle

or have difficulty. I explore women's individual standpoints and note their similar and contrary experiences. I also acknowledge that their experiences in STEM do not represent all women's standpoints, and do not in any way suggest that all their stories have been told. Insights to these women's stories are important because they provide a forum for analysis of what contemporary studies of women in STEM exhibit, and also offer a point of entry into further research on the academic and professional practices within the STEM fields.

\section{Feminist Standpoint Theory}

According to Harding (1991), feminist standpoint theory "focuses on gender differences, on women's and men's situations which give a scientific advantage to those who can make use of the differences" (p.120). It reflects women's experiences in space and time, governed by peculiar social relations (Hartsock, 1983b). This theory serves as a research approach which focuses on the lived experiences of women in STEM because it creates an understanding of what constitutes their social locations and realities that come 
with their individual oppressions. Using these women's lived experiences as the center for this research helps to strengthen objectivity because it informs and controls individual and socio-cultural biases (Swigonski, 1994). For this purpose, I use Harding's theoretical conceptions of feminist standpoint theory as grounds for my research study. Some of these include the following three conceptions;

First, women's different experiences as grounds of knowledge, have been ostracized from the conversations on scientific research as the starting points of evidence against dominant knowledge claims. Second, their individual standpoints should be used to criticize dominant epistemological claims which have primarily been observed through men's lives, race, class and culture. This would help in reducing the misconceptions and distorted realities presented by the natural and social sciences. Lastly, women's lives should be used as the origin of scientific problems, sources of scientific evidence and points from which the validity of knowledge claims can be tested. This meets the goal of enhancing research objectivity by discouraging an over reliance on exclusively masculine lives (Harding, 1991).

Having read what is said about women, standpoint helps to recover information about what they actually do; it makes the theories live. By focusing on what they have done and what they say about it, I will be able to find out if women are aware of the structures that inhibit their progress in STEM. What are these structures if there are, and what strategies have they used to succeed? As Harding will have it, "the strengths and weaknesses of the marble-its unsuspected cracks or surprising interior quality---are not visible until the sculptor tries to give it a shape she has in mind" (p.127). Standpoint theory 
therefore, serves as a point of entry the path for feminist researchers to get into women's lives as credible grounds, to critically examine the dominant knowledge claims based on sexism and androcentricism. It stands as a good means of examining the claims and evidence surrounding STEM structures which affect women.

It would also liberate knowledge on the 'leaky-pipeline metaphor', which was coined to represent the stages at which women drop out of STEM fields. Considering that this metaphor seeks to understand the structural inequities in women's education (Rosser, 1995), gaining insight to the strategies employed by these women to remain in the 'pipeline' would also highlight ways of curbing the under-representation of women in STEM. 


\section{Chapter 3}

\section{Methods:}

\section{When Literature and Theory Intersect}

"If someone wanted to know whether one drug is more effective than another, then a double blind clinical trial would be more appropriate than grounded theory study. However, if someone wanted to know what it was like to be a participant in a drug study [...], then he or she might sensibly engage in a grounded theory project or some other type of qualitative study."(Strauss and Corbin, 1998, p. 40)

\section{Overview}

In this chapter, I provide a background to grounded theory and its guidelines as presented by different scholars. I also offer a rationale for using this theory as a method and show how it was used to collect and analyze the data. In the course of this, I present the themes which emerged from my data after conducting interviews with my participants and conclude by making explicit how my data will be analyzed.

\section{Grounded Theory}

Grounded theory as developed by Barney Glaser and Anselm Strauss (1967) begins with the observation of a research situation by collecting qualitative data; in analyzing this data, the researcher looks at repeated ideas, takes note of apparent elements and further tags them with codes. Glaser and Strauss (1967) suggest that "initial decisions are not based on a preconceived theoretical framework" (Glaser \& Strauss 1967, p. 45). In essence this theory does not test hypothesis or theories but rather explores existing issues and builds on dominant patterns out of the results which in turn formulate the hypothesis and in some cases generates theories. This is to say that the researcher engages in a close study of raw data to bring out common patterns or themes which suggest dominant issues in the study. 
This is unlike other research methods which start off by consulting data through a theoretical lens and go on to make necessary changes. With grounded theory, the researcher lets the patterns emerge. According to Charmaz (2006) grounded theory enables us to understand issues "as our research participants' do- from the inside. Although we cannot claim to replicate their views, we can try to enter their settings and situations to the extent possible" (p.14). Thus with grounded theory, the researcher ought to keep an open mind when going into the field. The results or findings are what govern the guiding theoretical agenda.

Glaser (1992) summarizes grounded theory in the following ways: the need to understand what is out in the field by actually being in it, the value of understanding reality, the ever changing nature of research fields for both the subject and the researcher, the role of people in shaping their individual world, the world as a constantly changing place filled with complexities and the relationship between people's interpretations and their actions. The main aim of grounded theory as Goulding therefore suggests, (2002) is to "bridge the gap between theoretically uninformed empirical research and empirical uninformed theory" (p.41). An analysis based on grounded theory first comes from the data, it is then compared with theory and then judged within the research field. The conclusive arguments are based on the patterns which pose as the overriding theme. Grounded theory is good at getting into the lives of people and understanding their individual standpoints on an issue. It serves the purpose for my research. Below is a graphical representation of how this theory has been used for this research. 


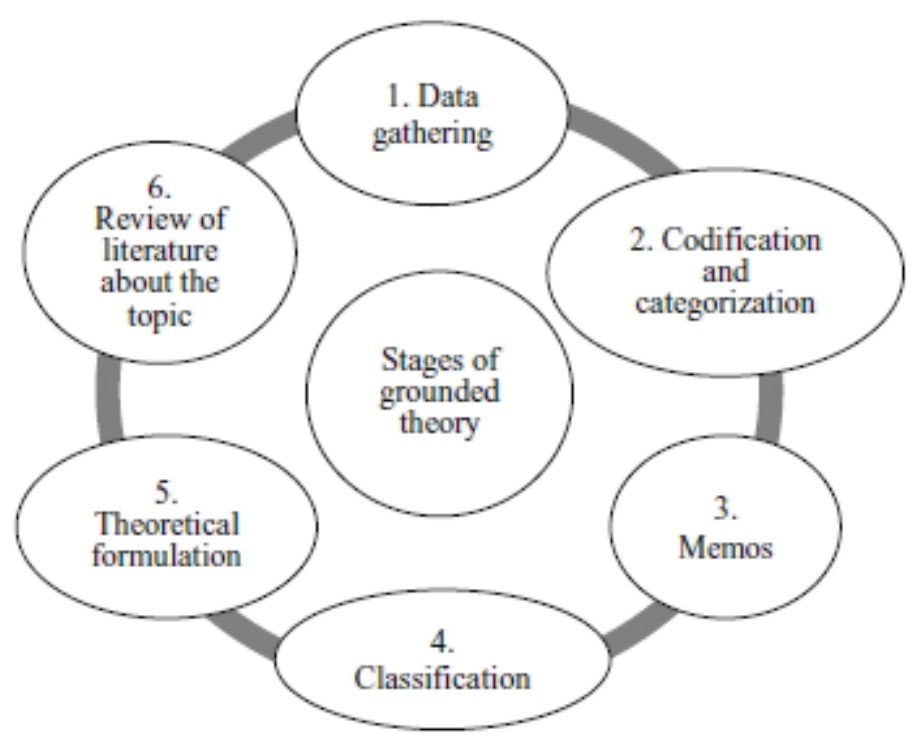

Figure 2: Graphical Representation of Grounded Theory

Marey-Pérez et al. (2014)

\section{Data Collection}

By engaging interview conversations, I observed scholarly arguments about women in STEM. Looking into these women's lives through their own lenses projected several perspectives of these arguments. This was in a bid to address the research questions which I reiterate here

- How do women in STEM 'negotiate' their identities in STEM as a 'male centered field?

- To what extent are they able to do this?

\section{Choice of participants}

I worked with eight women in STEM to understand their underrepresentation and to identify ways in which they have succeeded with that. Acknowledging that the minimal presence of women in STEM is wide across both academic and non-academic workplaces, 
participants in this research all come from academic workplaces. I consider that STEM careers all begin with academia and so begin with the varied perspectives and experiences of students in the field, and also get faculty perspectives of the same issues. Participants were purposively selected based on their academic and professional experiences. Four of these women were selected amongst female faculty and across different STEM disciplines. These included: mechanical engineering, chemical engineering, physics and biological sciences. The other four were also randomly selected from senior female students in STEM. Three of these groups of participants are in civil engineering, environmental engineering and medical engineering, while one of them is a post doc in the physics department. The senior female students were selected based on the conception that after four years in STEM, I will be able to understand their individual constraints if any, and they negotiate their constraints. My choice of a post-doc in the physics department was due to the unavailability of a female senior student. Grasping her thoughts on this issue proved to be invaluable to this research given the very sparse representation of women in this department. On a broader note, the reason for this diverse selection of participants is such that their experiences could echo multiple perspectives of what goes on in these fields.

\section{Table 2: Participant Sample}

\begin{tabular}{|l|l|}
\hline Students & Faculty \\
\hline Biomedical Engineering & Biological Sciences \\
\hline Civil Engineering & Mechanical Engineering \\
\hline Environmental Engineering & Chemical Engineering \\
\hline Physics (Post - doc) & Physics \\
\hline
\end{tabular}




\section{The Interview Process}

With IRB permission for conducting research on human subjects, emails were sent out to the respective participants seeking their consent to participate in the interview. Participant's participation was completely voluntary and they had the option of declining to answer any of the questions, to stop the interview or withdraw from it completely. However, none of the interview requests were declined and no question turned down. The interview questions were exploratory in nature and as grounded theory suggests, they were designed to identify themes and patterns in participants' responses to the structure and socialization of gender in STEM.

Participants responded to both prepared and spontaneous follow-up questions depending on the nature of the discussion. They were also not limited to just answering the questions posed, but were also given room to tell stories of their experiences. This was particularly important in that these women were able to express the way they feel about these issues. Such expressions were an important tool for reflecting on their individual standpoints. A collection of similar and different perspectives was important in comparing with findings from previous research. Interviews with faculty held at their respective offices while that with students was conducted the school library.

\section{Capturing, Storing and Securing Data}

Data was taken with the use of an audio recorder (with participants' permission) and transcribed with the aid of Transcriber-Pro, a software which facilitated the regulation of the tempo as I made notes. After each round of data collection, I noted down the key 
issues, a process in grounded theory known as "note-taking". These transcriptions were stored on a password protected computer only accessible to the principal investigator. The confidentiality of these interview participants has been maintained with the use of pseudonyms.

\section{Coding}

Coding is a basic step of data analysis which helps to narrow down data retrieved by creating clearer interpretative dimensions (Charmaz, 2006). It is labeling data with short codes which summarize the data. The codes are further used to build categories which are almost equivalent to themes or variables. The essence of this is such that it keeps the analysis open to several possibilities at this initial stage, and allows for new ideas to emerge. These codes therefore generate the skeleton of the analysis as they show how data is selected, separated and sorted. Grounded theory method advocates using several coding techniques to examine interviewee's accounts at different levels. The techniques employed in this research comprise of two main phases suggested by Charmaz (2006).

\section{Initial Coding}

Initial coding "involves naming each word, line or segment of data...during this phase, the goal is to remain open to all possible theoretical directions indicated by the readings" (Charmaz 2006, p.40). With this, I engaged in a line by line coding of the data; some of the codes taken directly from the participants (in-vivo codes) were also noted. This was helpful in making meaning out of my participant's experiences, as I was able to identify line by line, the underlying prospective themes embedded in the data. 
An example of how I explored the importance of having more women in the field was by building initial codes like "Suggesting gender equality", "Expressing need for more women", "Explaining cause of situation" out of participants responses.

Considering that grounded theory is a constant comparative method of analysis (Glaser \& Strauss, 1967), I constantly checked to ensure that the codes were closely related to the data and that they reflected what had been described. This helped me to identify hidden assumptions in my language, as well as that of the participants.

\section{Focused Coding}

"Focused coding synthesizes and explains larger segments of data...it is a selective phase that uses the most significant or frequent initial codes to sort, synthesize, integrate and organize large amounts of data... Focused coding is used to pinpoint and develop the most salient categories in large batches of data" (Charmaz 2006, p.40). With focused coding, I worked with the initial codes and selected the most frequent codes; that is codes which applied to most parts of the data. With these codes, I was led to go back and consult the data for the circumstances which evolved around these pieces of information. The next step of my analysis was building categories.

\section{Developing Categories}

"Categories explicate ideas, events, or processes in the data" (Charmaz 2006, p.91). Codes which had similar traits were put together into much broader categories. Examples of how these were represented include 'cultural biases, 'institutional biases and 'work/personal life balance'. These categories were continuously compared with the data to ensure that they clearly represented the data. The frequency of these categories in the 
data were relevant in adding weight to some of the issues presented. "Categories can carry so-called properties and dimensions. A property is a general or specific characteristic of a category, whereas a dimension denotes the location of a property along a continuum or range" (Strauss and Corbin, 1998). Out of the categories I developed memos which I later used to build my data analysis.

\section{Memo-Writing}

Memo-writing is the pivotal intermediate step between data collection and writing drafts of papers (Charmaz, 2006); it is constructed based on links between codes. A core category therefore, will be one which could later be found central to the study. It could take the form of "in vivo" codes (life words from participants) which borrow from already existing issues. From the coding examples above, linking codes or core categories could be tagged as 'gender equality' 'gender inequality', 'cultural biases, 'institutional biases, or 'gender imbalance'. Based on the core categories, I began free-writing on the main themes as seen in the extract below.

Understanding that these women sometimes struggle with an extra task of having to prove their competence to their male colleagues, makes me question the extent to which they cooperate with each other. Also, the idea that they are made to feel 'different' or rather 'isolated' suggests the presence of cultural biases. To an extent, it also portrays more liberty on the side of men. So I'm thinking...Could the feeling of 'isolation' be a reason why other girls are not attracted to the field? How do these women handle this problem? I think paying attention to what causes this problem and how they handle it could explain how they 'negotiate' their identities.

This writing process prompted me to look critically at the data. As the codes and memos accumulated, more data and codes like 'feeling different', 'feeling isolated' and 'facing extra challenges' emerged. I worked with both the new codes and other categories vis a vis the interview data, to critically examine and make sense of the data. 


\section{Sorting and Saturation}

When sorting I grouped the memos, like with like and arranged them in an order that made clearer, the categories that were dominant in the memos. These dominant categories became the core of my thesis as it helped create the best possible balance between the data, categories and theoretical statements about them. When the data collected no longer added anything new to these categories, I considered it to have 'saturated'. Saturation is "when new data no longer triggers new theoretical insights, and new properties of core theoretical categories are no longer revealed" (Charmaz 2006, p.113)

\section{Importance of Grounded Theory to this Research.}

I find this method appropriate for my work because given that findings of a grounded theory research represent real world settings, it serves the purpose of closing up the gap between the feminism empiricism and feminist standpoint theory as the working theoretical frames and my empirical research. As Dick (2000) argues, grounded theory "sets out to find what theory accounts for the research situation as it is" (p.6). In this respect it is like action research: the aim is to understand the research situation. This aim, as Glaser in particular states, is to discover the theory implicit in the data. As such, it has offered a forum for potential innovative discoveries of women in science and other related issues. Its explicit and sequential guidelines for conducting qualitative research made the research process feasible. 


\section{Some Arguments on Grounded theory}

Glaser and Strauss (1967) suggested that grounded theory researchers should go into the field without any pre-conceived assumptions of a theoretical framework so that the data will not in any way be distorted to suit the theory. However, while Glaser (1992) considers that studying the literature in advance gives rise to preconceptions which distorts the creation of new theory, Strauss and Corbin (1998) argue that although familiarizing one's self with the literature could enable sensitivity to relevant data, it could also block more creative ideas.

With regards to this study, I familiarized myself with relevant literature and used it as a guide to developing my research questions. This facilitated the development of codes and categories in the early phases of my analysis. This is not to say that I imposed the codes on the data, but rather that familiarity with literature as Strauss and Corbin argue helps in comparing literature and data to validate, negate or improve upon what is in the field. 


\section{Chapter 4}

\section{Data Analysis:}

\section{Making meaning out of shared experiences}

The overarching goal of feminist research is to capture women's lived experiences in a respectful manner that legitimates women's voices as sources of knowledge. In other words, the process of research is of as much importance as the outcome" (Campbell \& Wasco 2000 p.783)

\section{Overview}

This chapter details the paradigms and methods of my research process. Here, I offer interpretations to the information captured from women's lived experiences and echo their voices as new sources of knowledge. I present the major themes obtained from my research interviews and show how they relate to one another. Here again I reiterate my research questions

- How do women in STEM 'negotiate' their identities in STEM as a 'male centered field?

- To what extent are they able to do this?

\section{Data Management}

In this section, I present a picture of the data collected at various stages of my analysis using both faculty and student perspectives. I chose to separate this data so that the similar and different perspectives of both participant groups will be more evident. To this effect, I pay attention to the major themes which reflect both groups as well as that which pertains to each participant group. In this case, it will be looked at from student and faculty standpoints. 
The table below highlights the initial and focused codes and categories derived from the student data. The In-vivo codes were claims made by all student participants.

Table 3: Student Coding Process

\begin{tabular}{|c|c|c|c|}
\hline Initial Codes & Focused Codes & Categories & $\begin{array}{l}\text { In- } \\
\text { vivo }\end{array}$ \\
\hline $\begin{array}{l}\text {-Struggling to be recognized } \\
\text {-Feeling } \\
\text { frustrated/Afraid/ } \\
\text { Incompetent } \\
\text {-Admitting cultural biases }\end{array}$ & $\begin{array}{l}\text {-Facing challenges } \\
\text {-Admitting } \\
\text { presence of } \\
\text { cultural biases }\end{array}$ & $\begin{array}{l}\text {-Challenges } \\
\text {-Cultural Biases }\end{array}$ & $\begin{array}{l}\text {-No } \\
\text { institution } \\
\text { al bias }\end{array}$ \\
\hline $\begin{array}{l}\text {-Indicating female loss } \\
\text { of interest in middle } \\
\text { school } \\
\text {-Indicating difficulty at the } \\
\text { start of the program }\end{array}$ & $\begin{array}{l}\text { - Suggesting } \\
\text { issues with } \\
\text { academic } \\
\text { orientation }\end{array}$ & $\begin{array}{l}- \\
\text { Academic } \\
\text { Orientatio } \\
\mathrm{n}\end{array}$ & $\begin{array}{l}\text {-More } \\
\text { females } \\
\text { on } \\
\text { outreach } \\
\text { programs }\end{array}$ \\
\hline $\begin{array}{l}\text {-Suggesting gender equality } \\
\text {-Suggesting gender inequality } \\
\text {-Suggesting more } \\
\text { women should be in } \\
\text { STEM }\end{array}$ & $\begin{array}{l}\text {-Importance } \\
\text { of having } \\
\text { more women } \\
\text { in stem }\end{array}$ & $\begin{array}{l}\text { Student } \\
\text { perspective on } \\
\text { having more } \\
\text { women in STEM. }\end{array}$ & $\begin{array}{l}\text {-Fewer } \\
\text { women } \\
\text { in } \\
\text { STEM }\end{array}$ \\
\hline $\begin{array}{l}\text {-Suggesting men are } \\
\text { more competent } \\
\text {-Inclination for supportive } \\
\text { roles }\end{array}$ & & & $\begin{array}{l}\text {-Faculty } \\
\text { offers } \\
\text { students } \\
\text { aid. } \\
\text { - } \\
\text { Promote } \\
\text { talks to }\end{array}$ \\
\hline $\begin{array}{l}\text {-Assuming Leadership roles } \\
\text {-Admitting success }\end{array}$ & -Feeling successful & -Thriving in STEM & \\
\hline $\begin{array}{l}\text {-Indicating less love } \\
\text { for mechanical work } \\
\text {-Suggesting more love } \\
\text { for practical work }\end{array}$ & $\begin{array}{l}\text {-More love } \\
\text { for practical } \\
\text { work }\end{array}$ & $\begin{array}{l}\text {-Inclination } \\
\text { to practical } \\
\text { work }\end{array}$ & \\
\hline
\end{tabular}




\begin{tabular}{|c|c|c|}
\hline $\begin{array}{l}\text {-Admitting difficulties in } \\
\text { maintaining work/personal } \\
\text { life balance } \\
\text {-Indicating females do } \\
\text { more work } \\
\text {-Presenting women as } \\
\text { better organizers }\end{array}$ & $\begin{array}{l}\text {-Difficulties } \\
\text { maintaining } \\
\text { work/personal } \\
\text { life balance }\end{array}$ & $\begin{array}{l}\text {-Work/Personal } \\
\text { life balance }\end{array}$ \\
\hline $\begin{array}{l}\text {-Believing that society } \\
\text { is changing to favor } \\
\text { women } \\
\text {-Suggesting women have } \\
\text { an advantage over men }\end{array}$ & $\begin{array}{l}\text {-Believes } \\
\text { societal } \\
\text { changes } \\
\text { provides } \\
\text { women with }\end{array}$ & $\begin{array}{l}\text {-Societal } \\
\text { accommodation } \\
\text { of women in } \\
\text { STEM }\end{array}$ \\
\hline $\begin{array}{l}\text { Suggesting ways of overcoming } \\
\text { issues; resisting, ignoring, } \\
\text { determination } \\
\text {-Suggesting ways of increasing } \\
\text { female population } \\
\text { - Encouraging in-coming } \\
\text { students } \\
\text {-Offering challenges to female } \\
\text { outreach programs }\end{array}$ & $\begin{array}{l}\text {-Ways of } \\
\text { overcoming } \\
\text { issues } \\
\text {-Measures taken } \\
\text { to improve } \\
\text { female } \\
\text { population } \\
\text {-Ways of } \\
\text { addressing issues }\end{array}$ & $\begin{array}{l}\text {-Negotiation } \\
\text {-Improving } \\
\text { female under- } \\
\text { representation }\end{array}$ \\
\hline $\begin{array}{l}\text {-Narrating self/friends } \\
\text { experiences of bias }\end{array}$ & $\begin{array}{l}\text { Recounting } \\
\text { experiences }\end{array}$ & -Story-telling \\
\hline
\end{tabular}

Table 4: Faculty Coding Process

\begin{tabular}{|l|l|l|l|}
\hline Initial Codes & Focused Codes & Categories & In-vivo Codes \\
\hline $\begin{array}{l}\text {-Feeling belittled / } \\
\text { unrecognized } \\
\text {-Expressing feeling } \\
\text { of Isolation }\end{array}$ & $\begin{array}{l}\text {-Suggesting } \\
\text { discomfort }\end{array}$ & $\begin{array}{l}\text {-Uncomfortable } \\
\text { feelings }\end{array}$ & \\
\hline $\begin{array}{l}\text {-Suggesting improper } \\
\text { orientation } \\
\text { - Indicating few role } \\
\text { models }\end{array}$ & $\begin{array}{l}\text {-Suggesting Issues } \\
\text { with orientation } \\
\text {-Indicating few role } \\
\text { models }\end{array}$ & $\begin{array}{l}\text { - Orientation } \\
\text {-Role models }\end{array}$ & \\
\hline
\end{tabular}




\begin{tabular}{|c|c|c|c|}
\hline $\begin{array}{l}\text { - Indicating that there } \\
\text { are fewer women in } \\
\text { high positions }\end{array}$ & & & \\
\hline $\begin{array}{l}\text { - Expressing need for } \\
\text { practical experience } \\
\text {-Expressing love for } \\
\text { practical research } \\
\text { work } \\
\text { - Avoiding } \\
\text { mechanical/technical } \\
\text { work }\end{array}$ & $\begin{array}{l}\text {-Suggesting love } \\
\text { for practical work }\end{array}$ & $\begin{array}{l}\text { - Affinity to } \\
\text { practical work }\end{array}$ & \\
\hline $\begin{array}{l}\text { - Admitting to } \\
\text { presence of } \\
\text { institutional biases } \\
\text { - Recounting stories } \\
\text { of bias }\end{array}$ & $\begin{array}{l}\text {-Indicating } \\
\text { presence of } \\
\text { institutional bias }\end{array}$ & -Institutional bias & \\
\hline $\begin{array}{l}\text { - Suggests fewer } \\
\text { women in STEM } \\
\text {-Suggesting that } \\
\text { women are less } \\
\text { criticized for quitting } \\
\text { STEM than men }\end{array}$ & $\begin{array}{l}\text {-Giving reasons for } \\
\text { the under- } \\
\text { representation of } \\
\text { women in STEM }\end{array}$ & $\begin{array}{l}\text {-Under- } \\
\text { representation of } \\
\text { women in STEM }\end{array}$ & \\
\hline $\begin{array}{l}\text {-Presenting women } \\
\text { as relatively low } \\
\text { income earners } \\
\text {-Expressing } \\
\text { hindrances to getting } \\
\text { research funding } \\
\text {-Suggesting } \\
\text { difficulty to maintain } \\
\text { work/ personal life } \\
\text { balance }\end{array}$ & $\begin{array}{l}\text {-Suggests issues } \\
\text { with female } \\
\text { funding }\end{array}$ & $\begin{array}{l}\text {-Funding } \\
\text {-Work/personal life } \\
\text { balance }\end{array}$ & \\
\hline $\begin{array}{l}\text {-Suggesting men's } \\
\text { ignorance to STEM } \\
\text { issues } \\
\text {-Indicating that more } \\
\text { women get diversity } \\
\text { training }\end{array}$ & $\begin{array}{l}\text {-Presenting men's } \\
\text { ignorance to issues } \\
\text { - Suggesting that } \\
\text { more women get } \\
\text { diversity training. }\end{array}$ & $\begin{array}{l}\text {-Men's ignorance to } \\
\text { issues in STEM } \\
\text {-Diversity training }\end{array}$ & \\
\hline
\end{tabular}




\begin{tabular}{|c|c|c|c|}
\hline $\begin{array}{l}\text {-Suggesting } \\
\text { Inclination to } \\
\text { solidarity roles }\end{array}$ & & & \\
\hline $\begin{array}{l}\text { - Suggests } \\
\text { importance of having } \\
\text { more women in } \\
\text { STEM } \\
\text { - Providing ways of } \\
\text { increasing female } \\
\text { population }\end{array}$ & $\begin{array}{l}\text {-Stressing } \\
\text { importance of } \\
\text { having more } \\
\text { women in the field. }\end{array}$ & $\begin{array}{l}\text {-Importance of } \\
\text { having more } \\
\text { women in the field } \\
\text { - Ways of } \\
\text { increasing female } \\
\text { population }\end{array}$ & \\
\hline $\begin{array}{l}\text {-Suggesting how they } \\
\text { have handled } \\
\text { problems in the field } \\
\text { - Suggesting advice } \\
\text { to incoming } \\
\text { freshmen in STEM }\end{array}$ & $\begin{array}{l}\text { - Offering ways of } \\
\text { handling issues in } \\
\text { the field. }\end{array}$ & $\begin{array}{l}\text {-Addressing issues } \\
\text { in STEM }\end{array}$ & \\
\hline $\begin{array}{l}\text {-Defining success } \\
\text { level }\end{array}$ & & & \\
\hline
\end{tabular}

\section{Data Interpretation}

Feminist research seeks to respect, understand, and empower women. Therefore, feminist epistemologies accept women's stories of their lives as legitimate sources of knowledge, and feminist methodologies embody an ethic of caring through the process of sharing those stories

(Campbell \& Wasco 2011, p.778).

\section{Overview}

In this section I present participants' shared experiences as standpoints into new sources of knowledge. I recount that most of these experiences were grounded in their personal narratives (stories) which I insist are not a generalizable fact, but a reflection of issues which they face as women in STEM. Embedded in some of these stories were the 
'headwinds' and 'fifth-wheel' metaphors which I further developed to better understand and explain participant's experiences. On this note, I start-off by reporting on a combined structure of student and faculty personal narratives which as observed, portrayed consistent patterns of conflict, climax and resolution. The resolutions implicit in these stories are shared at the latter part of this discussion to show how these women 'negotiate' STEM barriers.

\section{Section A: Story Telling}

One of the ways through which these women expressed their experiences in STEM was by telling stories of their experiences. It should however be noted that they were not asked to use narrative structures in recounting their experiences. They framed some of their experiences by recounting personal narratives of conflicts, with heightened episodes of climax and went on to explain how they negotiated these issues. This story-structure of conflict, climax and resolution is important in interpreting the data because it gives a sense of what is important to these women. Moreover, the stories also provide information about STEM structures which can be understood better when analyzed in these structural patterns. Without this, some of the causes and effects of these STEM structures could go unrevealed or remain hidden. Hence story-telling imparts an understanding of these women's experiences in ways that better expose and detail their experiences. In this section I present some of their personal narratives using the dominant patterns of conflict, climax and resolution. 


\section{Conflicts}

Several patterns of conflict were identified in these women's stories, a majority of which start from external factors like societal ideologies and ended with intra-personal conflicts within the participants. All of such conflicts, however contribute to the way these women negotiate and represent their identities in STEM.

\section{Intra-personal and Ideological conflicts.}

The stories below highlight Intrapersonal conflicts (conflicts within self) which these women experience in STEM as a result of already existing core beliefs strongly inculcated in the minds of people in the society at large. The ideologies which pre-suppose that women are 'second-placed' in society cause tension in the minds of these women as they challenge and question their abilities to thrive in STEM like their male colleagues.

Lynn, a female faculty, suggests that the conflicts which go on in her mind limit her ability to properly communicate with her colleagues during meetings because the men usually take the lead and would regard her as 'bossy' whenever she has to talk.

Well again from my reading uhmmm...when presented with two resumes, one with a woman's name, one with a man's name, there's a decrement that the woman's resume is rated lower. When asked what salary to give to two people with identical records, they do these studies and the woman is given the lower one. When women are interviewed and they follow a script and they do these psychological studies and they do the same thing with the men. Whatever the women do is always reported back in the context of the womanly things you know like you know...she was too harsh, she was too brash whereas the man with the same words was a leader and all those annoying things... and headed the table issue...you know when they ask her subjects whose the head of this meeting if they saw a man at the head of the table it's the man at the head of the table, if they saw a woman at the head of the table it's the woman at the head of the table. But if it's a mixture of men and women, and there's a man at the head of the table, then he's the head of the meeting but if it's a mixture of men and women, there's a woman at the head of the table, half the time they pick a man seated somewhere else. So all of these social science studies 
show that we are not, I am not in the same world as my male colleagues at all and I feel it every day. I feel it every meeting when I speak, I have to consider how my speech is being received... But I have to think how is it gonna look because bossy big mouth Lynn is gonna be talking and dominating the meeting.

In the same light, Sarah another female faculty has conflicts within herself because she is made to feel less recognized in group meetings with her colleagues. With only one female colleague amongst other male colleagues, she finds the need to 'work a little harder' to be heard in meetings with their male colleagues.

I noticed with Vera and I when we hold meetings 30 of our colleagues don't help and I noticed that she and I don't talk. We use a chat window on a computer rather than talk. For example when I run a meeting it's not like people talk over me when I run a meeting I run a meeting and that's clear. But in these captions you know we may be over talked easily I think we have to work a little harder to be heard.

From a student perspective, Tory believes women in STEM have intrapersonal conflicts after constantly questioning their presence in the field. When they are made to feel inadequate in the field, they contemplate other options out of STEM, where perhaps they would be treated better. She admits having these thoughts sometimes and wonders why she is still present in the field.

If someone was discriminating against you know you just have to... at least have the topic out but if you think about it right... there are gonna be options... staying in the field or sometimes people don't treat you as an equal person so then you just go out and get another street job then you earn money and you go home... unless you really want to stay in academia you're not gonna be constantly fighting these doubts, you'd just leave and that's why...you know there are these obstacles after obstacles then all of a sudden it seems like they even get so much further ideas why ...you know why would I have to be here?

Having grappled her way through her studies as a mechanical engineer, Ruth, a female faculty finally got a sense of what engineering was all about when she started working in industry. She contemplated her ability to lead a group of men at her workplace, because she felt they would not find her competent enough. She recounts being able to maintain her 
position as a leader because she was 'lucky' to have a male boss who constantly encouraged and believed in her.

I had a boss at one point in my career when I was working with automotive who...I think truly had more confidence in me than I had in myself and so he will push me to take on bigger challenges even when I thought I wasn't ready for most of them... you know...he was very supportive, and he would convince me I could do it so...he would promote me into positions that I was like' I'm not ready for this' but he saw that I was.

\section{Conflict of power}

In Lynn's opinion, it seems apparent that society promotes a conflict of power between men and women in STEM. She indicates this when she pre-supposes the idea that society encourages men to obtain STEM education, and in turn encourages women to drop out. It becomes a question of power even more when she adds that these perceptions, promote economic imbalances between men and women. Lynn presents this socio-economic disparity between men and women in STEM when she says

There's nothing more satisfying like being a mum and we need more moms like you to volunteer in the schools and to make sure that society works well all through... all the things my mother did...all through but if a man at 35 when his kids are young suddenly says this is ridiculous I'm gonna stay at home with the kids and my wife is gonna stay in her job, he's gonna get...he's gonna spend a lifetime with that wind in his face you know ... when people say hey what do you do bill? and he's gonna say I stay at home with the kids for $20 y$ rs and they are gonna feel like what mental illness do you have you know? What are you covering up? Are you alcoholic are you? Is that a code for I was in prison? You know he's gonna get all kinds of negative push back and she's not. She's just gonna be... and then when she goes to dinner parties... and people say what do you do and she goes the kid's fine and on with life you know. So it's easier to drop out if you are a woman than if you are man. And so the people who don't drop out are the ones at the top of the distribution who are like...I will not be happy you know, it's easier to drop out. 
The clash of power between genders in STEM is also recounted from Sandra's student perspective, where she makes the claim that that her male peers take over her work once they are done with theirs. Despite feeling that she is competent to engage in equal physical labor as men, she has conflicts within herself about this and believes that it is a cultural thing' which is gradually changing.

I think there's a lot of things that people just don't see that women are fit for just very general uhmm...I work working on building a water filtration this summer and every single time I had a guy that would be done with whatever he was doing...he'd come and take over, like if I was drilling something they'd have to come over and take over from me and it's just kind of that mindset of men should be doing like the physical labor uhmm...whereas women are perfectly capable of doing it..uhmm but that's just kind of like a cultural thing that we are trying to shift away from uhmm..But it's a very slow shift.., so I think it's happening it's just very slow... Uhmm I was offended a little bit, but not. I mean...I know they weren't trying to offend me so it's one of those kind of I'm offended

\section{Ideological and Psychological Conflicts}

In Lynn's opinion, women in STEM have psychological conflicts which arise from the ongoing cultural stereotypes which society has labelled them with. She argues that women read meaning into the way society has designed their gender and get to believe it once they fail to challenge it. Thus she suggests that psychological conflicts are caused by a lack of confidence, which builds out of culturally ingrained stereotypes.

Frankly I think women don't persist in STEM fields because they read the culture and the culture tells them they don't belong. They read the culture... the culture tells them that they are supposed to be pretty, they are meant to be...ehmm pleasing they are meant to be sociable and sweet and differential and soft spoken and they read that and if that at all matches with their self-image, they probably do it, probably hardly... If it's a mismatch, where that doesn't seem to make sense to them, then they'll persist through those cultural signals and then they'll face that headwind continuously. I think that the message to women is relentless you know. It's depressing because you can brush it aside and ignore it but off course you are not perfect and so you have flaws and so when it the message from the culture matches 
something is true. Like oh this is hard for you, you are not really that good at something then the two things amplify and then suddenly you say ohhh it's all true. I don't belong.

\section{Climax}

Stories which reflect the climax of these women's experiences represents the decisive moment at which they formulate ideas about negotiating conflict. It indicates the extent to which these women are willing to implement strategies to better their experiences in STEM. I present an example of a conflict which led to such a 'decisive moment', and add other instances where participants present their decisive moments without clearly bringing out the root cause of the problem.

Having understood that gender roles have been so 'ingrained' that women just fit into that reserved for them, Becky takes up the challenge to see that female students perform the same tasks as their male peers. She suggests that men need to become aware that this poses a problem and work with women to fix it.

I think sometimes women, young women allow themselves to be sort of taken care of and other times men just assume the role of men ... uhm... we see it like when we take groups of students out in the field and we have field work to do and a lot of times it'll be the guys that grab the gear and jump in the water and the women stand on the shore with a note book and u know...I'll have to yell at them and say ok "we'll do this for five minutes"... but then you'll all switching and then the women are in the river with the gear in ... but I think it's so ingrained in a lot of people that those are their roles and they just instantly assume them ...I think that's everywhere ... I think that's discouraged everywhere one of the things I think that is a hindrance is that men don't realize what's going on.....and that person who I used to teach was on that field trip when we took the kids out to the river and all the men jumped in with all the gear.. And all the women are standing at the shore and I yelled at all of them and he is in the river with the guys and he doesn't see it... you know and so if your colleague doesn't help and see it and involve and engage .... and so if we are 
not working at fixing that and demonstrating that in the classes then how will the women and the men in those classes see that?

Others like Ella, recount stories of such decisive moments without much details of the problem. She dropped out of mechanical engineering because of the difficulties she had in her first year. After several contemplations, she is now comfortable as a bio-medical engineering student.

I think during my first year I was taking some classes that were tough for me... I think the mechanical engineering class and a couple more. I really considered dropping and doing something like nursing which I felt was relatively easier. Also getting involved in it was hard ... as a transfer student I had to meet new people and that was tough. But now its fine I feel more involved in activities in school.

Another instance of a decisive moment without a detailed narrative of the problem is Tory's decision to 'take a step back' and live a 'normal life'. This is based on her opinion as a post-doc, that success in her field is all about research and competition which often times doesn't make people happy. She indicates doing whatever will make her happy even if it means she has to 'sacrifice family'.

Sometimes people aren't really happy they are always like competing...I'm ok to take a step back you know and still enjoy what I'm doing but I still make contributions to ... you know our field in physics and I don't need to be caught up competing.... I don't wanna spend $120 \mathrm{hrs}$ working and sometimes that's what's needed if you wanna be at the very very top and I think throughout the years I've come to realize that I've come to realize that I'm ok with not being the best of the best. I mean if it means I have to sacrifice family and just you know... just normal life... I dunno I am happy to take a step back and say ok... as long as I am making contributions and I'm useful I would still like to have fun.

Unlike all other participants, Lynn strongly argues against giving any advice to incoming female freshmen in STEM. She expresses disdain at the fact that female students have to 
constantly be reminded about STEM structures. While insisting that men need to start getting their fair share of these talks, it dawns on her that she could personally embark on talking to them about these issues.

I'm not sure I'd tell them anything.... (Long silence) Because it might be better to pretend that it's not a problem for them. Actually I feel like I would wanna say something to the men. I'd have to get the women out of the room so they don't have to hear it. I will tell the men that this schema exists, and that they are getting an unearned advantage... by being male and right now when you are a freshman and a sophomore, you're gona say the men and the women are equal in fact the smartest people in my class are women. Yes they are... The smartest women in the class in fact are gonna be women. Because they are people who have been pushing up already against the headwind and they are better than the men. And you are gonna think that this gender problem has been solved...well let me tell you men that we taught that was true 30yrs ago and the women in the 70's thought it was true 15yrs before that and it wasn't true either time and it's not true now. So when you wake up in mid-career and some of the women are gone, you're gonna remember what I'm telling you right now and I want you to believe that this really exists and I want you to be a part of the solution. Don't wait till you have daughters and it pisses you off that your daughter is discriminated against. Be part of the solution now. No one has ever asked me to talk to a group of men though. But maybe I should... Some will remember because they are not doing it deliberately. But the men are never gonna hear it unless you sit them down. the positive thing about talking to a room full of men is that some fraction will like take the data seriously and it'll lock in somewhere and when they are in the room and a decision is being made, they might go wait a second and that might make a change. We need more people doing that.

\section{Resolution}

Women in this research make sense out of the conflicts which they experience by resolving them via several 'negotiation' strategies like determination, competency, accommodation, and colloquy. A common understanding of negotiation is two or more people having a dialogue with the intention of reaching a common ground on an issue. 'Negotiation' in the context of this female participants' experience, however suggests ways through which they address the 'headwinds' such that in reacting to it, they are still able to maintain neutral grounds as their male colleagues in the field. "A focus on the nature of academic STEM 
environments or climates is important precisely because features of settings can be changed, and probably changed more readily than stereotypes can be" (Sekaquaptewa 2014, p.1).

\section{Determination}

This stands out as a major driving force for these women's involvement in STEM. The firmness of purpose or rather resolute approach which they employ towards their career and education in STEM was noted from all participants. They find it important that women believe in their abilities and also be made to understand that they can achieve all they set out to do. Because they suggest that 'women have an extra task of pushing through barriers', they assert that love for one's field and then determination remains key to success. To this regard, Ruth a female faculty proposes an advice for incoming freshmen students.

I would say to any student focus on doing what you are all doing you know, uhmm... and then it becomes easy to kind of push through those barriers, but if you don't really love it, then it just becomes this huge burden. You know... and then you know it's not fun, it's stressful and all those things. So I think the first step is...to find what you love doing no matter what it does and then just persist you know...whatever barriers exist in that field...in that area. If you love doing it don't let anything in your way. So some things will come easier than others you know but uhmmm... if you love building things and tinkering with things and envision yourself working as a mechanical engineer, you know... there is no reason any other is gonna stop this to get in your way, unless you let it.

Sara, another female faculty also expresses her determined attitude towards her field when she advises incoming freshmen students not to quit because they feel incompetent. She adds feeling like this once, but did not give up on her determination.

They should stay with-it if they like it and that they should not quit if they think they are not good enough. They might not be good enough but to quit and say they 
will not make it is wrong. I was about to quit physics and someone said after my PhD... I had a good friend he advised me about it.

Drawing from her post-doc perspective, Tory insists that students should stay in their fields of study if it's what they want and if they find it enjoyable. She adds that there would always be 'negative people' but remains firm on her perception that students should strive not to be affected by them. Ella on her part, encourages female students in these words

I will encourage them...I will tell them not to let the guys intimidate you... don't let them bother you... don't think of them as different from yourself. You might not understand some things like they do but ask questions. I will tell them to stick with it.

Sandra, another female student also shares this opinion when she insists that students should be 'dedicated', have 'motivation' and 'not be scared to ask questions'.

\section{Competency}

The urge for student participants to prove their competence in the face of these conflicts also stood out as a motivating factor for them. Having 'read the culture', some of these women indicated wanting to make the world know that even women can do it. Tory insists;

I want to show them that if you want to do it, you can, that it's not just men that do physics. So much like it's not just men that can be mechanics...you know what if you are really interested you can figure it out yourself and you know. There are people out there who can help you.

Besides being very determined Janice, is moved by a competitive urge to prove to her male classmates that she is capable of becoming an engineer. She nurtured this competitive urge to prove that she can also be an engineer while on a robotics team with mostly males

Because I really want to really be an environmental engineer. I have a lot of determination, I am also very prideful. So I considered switching majors and then moving back home but I ...as I said I was in robotics with mostly males and I was very much like no I have to prove to them that I can be an engineer and that I can 
do this ..uhmm and I don't talk to any of them anymore but to me it's still I have to prove to them that I can do this... whether they'll know or not.

In the same vein, Sandra also wishes to "prove to the men that you can do it, that it's not just them who are up to the task." Ella believes that there is no difference between herself and the guys and so finds no reason to feel intimidated, while Tory believes all she needs to do is "just kind of prove to them that you know...you are an equal to them". As Sekaquaptewa (2014) argues, when science is depicted as a place where one must engage in "intellectual battle" to "defend one's work" from "attack" and to "beat others" to the publication finish line, one can see the mismatch between the agentic qualities seen as required for STEM success and those expected of and encouraged in women. (p.2)

\section{Accommodation}

Unlike the determined and competent aspirations of the others, Becky admits "waiting patiently for changes to be effected', while Sarah on her part, suggests that feeling inadequate and thinking 'others are better than you' is a feeling one eventually gets used to.

I have seen many people leaving the field saying they work too many long hours, not enough money, recognition and I always feel I'm not good enough. It's a feeling you need to get used to and that you always think other people are better than you. But that's by the way true for any field. Some of my friends left physics and they say it's not as bad as it was in physics.

After a careful observation of unwelcoming manner by which people around her talk, Tory admits accommodating it when she chooses not to take things personally.

I don't take things personally despite when you know...if ...I've heard people that pass on insults to each other and they still are not working that...and I also realized that sometimes they don't mean it... because sometimes they apologize because they didn't realize how terrible it sounded when they talked to that person... and I've 
come to a conclusion that sometimes scientists are just cruel with when they say things...

In the same vein, Sandra admits that she struggles having her male classmates take over her work whenever they are done with theirs. Despite this, she says "I know they weren't trying to offend me so it's one of those kind of I'm offended but I know you are not trying to offend me...so I was trying not to be if that makes sense".

\section{Colloquy}

Encouraging forums where these women come together to encourage themselves about the issues in STEM was one of the ways through which female students get a sense of belonging in their respective fields. As all four students recounted, female faculty and advisors occasionally give talks and motivate them through their academics. Moreover, they also mentioned having clubs, organizations, outreach programs and magazines which they participate in to promote an awareness to the females that they are as capable in STEM field as the men are.

\section{Section B: Metaphors}

The use of metaphors as a figure of speech makes implicit comparisons between objects based on some common characteristics. The use of metaphors as a figure of speech makes implicit comparisons between objects based on some common characteristics. In this light, metaphors used in this research make implicit comparisons between female participants and objects, which have common characteristics that can be related to their experiences in STEM. This is based off the conception that metaphors are pervasive in our lives, both in terms of the way we think and act. As earlier mentioned, to better understand 
how these women negotiate STEM structures to maintain their academic pathways, I also examine the 'leaky pipeline' metaphor which has been coined to describe the different stages through which women drop out of their STEM education and careers. Although it is argued to help 'structural thinking' and 'policy making' in and around STEM education (Pawley, 2011), it focuses on the women who leave STEM and does not take into the account the causes of the 'leaks'. Hence, to an extent, it does not address the underrepresentation of women in STEM fields. Insight to the 'negotiation' strategies employed by these women to remain in the 'pipeline', informs ways through which the under-representation of women in STEM could also be curbed. Out of these 'negotiation' strategies, the 'head-winds' and 'fifth-wheel metaphors' emerged. I present the contention that they stand as better alternatives to 'leaky-pipeline' metaphor because they focus on what these women encounter and how they negotiate them.

\section{Headwinds}

'Headwinds' as a metaphor was derived from one of my participants who constantly used it to represent the ways in which women experience gender differences which work to their disadvantage. 'Headwinds' in literal terms refers to "a wind blowing from directly in front, opposing forward motion". However, in this research, it refers to a progressive negative obstruction which women in STEM face in their academic pathway as a result of dominant stereotypes. In other words, it is an ongoing effect of stereotypes on women in STEM. Based on their experiences with the headwinds, their standpoints therefore informs a better understanding of how stereotypes and biases operate and so strengthens objectivity. In other words, these women's standpoints present a 'less distorted' 
or 'partial' understanding of their encounters in STEM. By looking at these women's experiences of the 'headwind', I connote the idea that it is a better way of talking about women's experiences than the pipeline metaphor. This will be discussed in the fifthchapter.

\section{Faculty Perspective of 'headwinds'}

Faculty admit experiencing 'headwinds' through most stages of their academic career. Unlike the students, who admit having support from outreach programs and female supervisors, female faculty participants express the challenge of having little or no support managing advisory and female outreach service programs.

\section{Imbalance in diversity outreach commitment}

The female faculty participants admit taking the diversity training and setting up outreach programs to boost female students' interest and make them believe that they are up to the task. They however also contend that they are put in these roles because there are only a few of them available to represent the women. According to Sarah,

If you have five people giving talks and four of them are women you know that probably those four are the only four in the department. ...if you go into academia as a female professor it's almost suspected that if you would do some sort of like mentoring because there are so few of them and you are trying to increase the number and you always end up getting put into that position where you need to lead this discussion

Lynn also seconds this by saying that "we're not at the numbers yet where we can start saying that we have you know...equal men and women and we don't have to direct all the recruitment towards the women." In Ruth's opinion, “ lots of girls go to nursing or some kind of medical degree or they go for humanities or social science I think just because 
that's what they interested in, it is just a portion of women who are motivated by this math and science you know..." Ruth is also not convinced that the department would someday be even. Becky indicates that she feels obliged to participate in female outreach programs because of men's little or no inclination to do so.

There are men in this department that have been here for years, don't take the diversity training and so therefore can't take sit on the committee, can't do service and so... get some done...there's less that do take the training and our ....that's one of the thing

Lynn adds that men "always be like...oh...Lets' send the women to the women's ...you know..." because of this attitude, men are said not to take the diversity training which as an effect makes them unable to sit on the committee for recruitment of new faculty. In effect they offer little or no support to women in this regard.

\section{Work/Personal Life Balance}

Balancing work and personal life also turns out to be one of the 'headwinds' which female faculty experience, as they admit that it is not an easy balance. They argue that with the coming of social media, it has become easy for one to be reached at any time of the day, even outside working hours. With limited time available during the day to respond to emails, the need to respond to these emails after working hours becomes inevitable.

They contest that there would always be 'trade-offs' with this issue depending on what pops up as priority at any given time. In some circumstances they would excel at their academic work, to the expense of their personal work and vice versa. Becky indicates this when she asserts that; "Last semester, I completely failed...I had no personal life ...I was here every weekend Saturday and Sunday teaching, grading, working on committee work 
... I had no life and if it wasn't for sabbatical this semester hmm...I'd still have no life.”

Lynn adds that,

Well it turned out that I didn't have kids and my husband is also a professor in this university so there's no balance. My professional life is my life, I mean I spend a lot of time on my professional life. I am always reading, I am always improving my classes, I am always working on assessments and ... issues and community work

This indicates that Lynn finds it less complicated to balance work and family life because she has no children. Ruth seconds this by saying "people who really have these obligations are those who have children or parents to take care of". She sees a need for work/life balance only in the presence of kids.

\section{Unequal Pay}

One of these women indicates that there exists cases of unequal pay in her department. She insists that it is unfair to have men in her department earn huge salaries without teaching while she does a lot more work both as a teacher and chairing committee meetings. Moreover, having waited for changes to effected, she lets out her feelings regarding these issues when she says "you know it amazes me one of those smart CEO says well just wait until they retire, you know it's like my whole life here I've been waiting till some of these sluggards retire and I'm still waiting and I'm nearing retirement so...I dunno". This suggests her level of patience and uncertainty about possible changes in the system.

\section{Male Resistance to Female Authority}

Having worked in industry for an equal length of time as in academia, Ruth found that being a boss to a male dominated group of workers was a challenging task. During several 
occasions, she felt they doubted her competence and so did not feel confident working as a female engineer in a male dominated workplace. She indicates this when she says

Well things like...you know...all of a sudden you are the...the...supervisor or manager or leader over uhmm male engineers who have been working in the field $20 y r s$ longer than I have and so they look at you like "who are you to be my boss?" you know so uhmm.. so think a man could step much more easily into that kind of role, I think it was more challenging for me to prove myself capable of being in that role. So it took more time, it took more effort uhm...to win their respect whereas I think at least in my experience if they were to put a man in that role, they just kind of by default are given that respect. So I think women have to work harder to gain respect of their colleagues.

Sarah also recounts a point in her past when she had to work with male colleagues, and indicated that she was assigned to take care of the food. She believes it was the case because she was the only female on the faculty. This suggests a reason why she adds that "women have more community work although it would seem that it is because there are few women to take up these roles". The restrictions which Lynn faces when she has to speak out in meetings is due to the resistance which she gets from her male colleagues during meetings. She expresses this when she says "how many other people dominate the meeting? Oh yeah...it's just this guy or just that guy' She adds that if it's a woman, it would be read that "women are too bla bla" She finds this 'annoying'.

Fully aware that these perspectives are not representative of what goes on STEM as a whole, it at least offers a glimpse of how these women perceive and experience the issues going on. Apparently the different kinds of 'headwinds' which these women experience could account for the 'leakages' in the pipeline. 


\section{Student Perspective of 'headwinds'}

Students reject the notion that institutional headwinds limit girls from getting into STEM because as Ella opines "most schools make it pretty easy for women to get into STEM programs these days'. For Sandra, if at all there is discrimination, then the students probably get uncomfortable with the way things work. She argues that the department does not make things tough for the women. "I do not think there is much discrimination or anything like that here. It's the girls really uncomfortable with it...I do not think it is set up tough for women". Janice on her part admits having some hard professors although their hardness in her opinion is directly related to the class. "I had a couple hard professors but you know that's just because usually that's because just it's a hard class but I never, not gotten along with my professors always like -ask them questions and are willing to work with you usually." However, Tory who is in her mid-career as a post-doc looks at it from the standpoint that 'the problem is with the older generation'. She keeps a brighter look of things and believes that institutional headwinds have no effect on her.

Considering all four students perspective, it remains a possibility that some of these structures which limit female students from getting into STEM are gradually fading away. However, beyond this, students already enrolled in STEM still indicate having challenges in the different ways outlined below.

\section{Work/Personal Life Balance}

My conversations with student participants also exposed the reality that balancing work/personal is not an easy thing to do. This is the case for Tory who says that conducting experiments take up a great portion of time because it requires her to do a 'constant check 
at intervals to ensure that everything is turning out just fine'. Moreover, she is required to travel out of the country to 'represent experiments' and 'give talks' which all limit her from spending time with her fiancé. To this she adds:

"When we are together we are like ok let's not check our emails, you know not read anything we are spending like this amount of time together. That's what I mean it's hard because sometimes you have to make sure you don't overwork yourself."

Tory also contends that social media has made it easy for school work to get into her personal hours. She has been resistant to getting a smart phone in order that the urge of checking work related emails outside her working hours can be reduced.

Others like Ella try to make school and work both priorities and so sets equal time for both because she has to work to fend for her school and other living expenses. However, Sandra shares her ability to properly manage her time. Being involved in many campus activities such as broomball, pep band, undergrad student government and undergrad society for environmental engineers, she maintains having a good balance for all these activities.

"I have a pretty good balance this year...got a schedule that I'm mostly done with my homework by Friday night so I have the weekends pretty free other than broomball and pep band but those I consider to be fun so it's ok to me."

One in four student participants confirms being able to manage her time effectively after four years. This suggests that it is possible after a long period of dedication to do. However it worthy to note that is not applicable to all the participants.

\section{Academic Orientation}

All fours students recall having a tough time during their first year, as they struggled to grapple with their school work. Their experiences also suggest that they face the headwinds when some professors do not take them seriously, and also because of the 
difficulty in catching up with assignments using 'general guidelines' as opposed to having 'direct examples' which they had they been used to. More still, the overwhelming nature of these disciplines is what in their opinion makes most of the students drop out, or prompts them to take relatively 'easier' options like nursing. Ella shied away from mechanical engineering because it turned out to be her hardest first class. This to her is one of the reasons why she decided to stay in Biomedical engineering. While Tory complained of being the only girl in her under-graduate classroom and having difficulties working with 'non-co-operative people', Sandra contends that it took her four years of her undergraduate education to figure out how to make college work.

\section{The fifth-wheel}

The second metaphor explored in this data is the 'fifth wheel metaphor'. Also used by one of my participants, I found it to be useful in explaining participants feeling of isolation, their opinion of difference and reaction of their male peers/colleagues to this difference. Adding a fifth wheel to a car which accommodates four is an impossible task to do. However, in order to make the fifth wheel useful, it could be kept as a spare, away from the others while they are in use, and only brought out when the need arises. The fifth wheel is isolated from the others not necessarily because it is different, but because it is not needed at a particular point in time. As these women suggest, their feeling of isolation emerges not because they are necessarily incompetent as they are made to feel, but because

these feelings of incompetency coupled with their minimal presence makes it difficult to co-operate with their male colleagues. Hence the 'fifth-wheel' in this sense also suggests that these women struggle 'fit in' to be 'recognized'. They express discomfort when their 
opinions are not taken into consideration. I use this analysis to examine how the women in this research present themselves as 'fifth wheels' in their various academic disciplines, and further contend that an understanding of this would also help in sealing the 'leakages' of the STEM pipeline. The fifth-wheel metaphor as a better alternative to the leaky pipeline metaphor will be further examined in chapter 5 of this research.

\section{Faculty perspective of the fifth-wheel}

I make reference to this metaphor as used by one of my participants to describe her feelings of isolation, not being welcome or rather being left out from her group activities. She uses this metaphor to explain the difficulty she encounters while working with her male colleagues. Becky had to give a workshop on how to identify newly hatched fish based off a '744 page' which she wrote. She feels left out and unacknowledged.

I agree with the day about nailing the jello to the wall... I was like what? I don't even know what that means... what are you three talking about the jello to the wall, I have not a clue and here we are all supposed to be working on this workshop and just uh..I dunno... it's like they are all in a different world and sometimes I feel like I am just invited like as a fifth wheel and you know... I wrote the book. There's one other fellow that's involved in the project emailed like forty people in our field... and he said I'm getting together and... We are gonna do...uhh...We are gonna add photos to the level of fish key..I emailed back and I said that's great well I'm up for photos but what if you picked up the phone and just called me and said you'd like to do this because it is my name on that thing and yet there's... I dunno it always strikes me that when it comes to men they are very sure to acknowledge each other and yet when if there's a woman around it's like...ohh....we'd just take that and use it... and like hellooo... I emailed all of them and said "excuse me I'm not dead yet...could you be a little respectful? So... it's frustrating...

More still, when she adds, "I think I have heaps more work and I think all of the men whine and get out of it or have kissed the right butt..." she suggests an uncooperative atmosphere with her male colleagues, who treat her differently. She also adds that she feels 'invisible' 
having to teach the same class with a 'charismatic male'. Her perception of this is that they do not make her feel recognized in their teaching obligations and duties.

Well here's another thing I have seen after years of being in classrooms and especially if I team teach with a male and if that male was at all charismatic ...uhmm... the women in the class ...I'm invisible and I don't teach with one of these people anymore because I feel so awful all the time.. I think it happens every single time and it's like ... and I don't know how to...how to approach that

Other female faculty also recounted experiences which presented them as fifth-wheels in their various disciplines. In Ruth's opinion, her experience as a female engineer 'is always a challenge' because there were always people who perceived her as being less capable than her male colleagues. Having been in the position of a boss to male engineers in a company, she adds that it takes her relatively 'more time' and effort for her to earn the respect of her colleagues, which she believes would be automatically given to a guy in her position. While Sarah thinks she needs to 'over-talk' to be 'heard', Lynn strives not to 'over-talk' to be misread. Lynn contends that the issues women face in STEM, gives them the impression that they are not up to their male colleagues expectations and are really not where they belong. Also, by suggesting that their male colleagues do not take part in diversity trainings and also do not support outreach programs or sit in as advisors to incoming female students, they acknowledge being different in the sense that specific roles in STEM are assigned to them.

\section{Student's perspective of the fifth-wheel}

Students also provide examples where people make them feel that they are different in that they are 'less capable than their male colleagues'. Sandra insists that "It becomes 
challenging competing for co-ops and interviews where you stand as "one girl against ten guys" and...

It's kind of hard to make them realize that you worth it you know what I mean like they look through that... but you kind of have to bring in something to the table and I think that's definitely challenging when you're the only one against up with men so...

Ella suggests the existence of stereotypes which insist that "girls aren't as good in math and science" and are also "not capable of working in STEM fields". It is probably because of such stereotypes that she indicates being "put below" the guys in her classroom. She however refers to this as a "natural balance" which has nothing to do with teacher's influence.

Another issue raised to this effect is the notion that women are supposed to be the "figure of society" such that they have to put on formal dresses like heels and skirts while in the field. In Sandra's opinion, by putting up such standards the women may feel inclined to look "super fancy" on interviews and even on the job; while men work in the field with "jeans" and "baggy shirts". She finds it necessary that women dress in ways that suit their working abilities and not be inclined to suit constructed standards of dressing. This suggests that women are treated differently with regards to their dressing expectations in the field. Tory on her part, complains of having been the only girl in her under-graduate classroom and faced difficulties working with, non-co-operative people. 


\section{Chapter 5 \\ Discussion and Conclusion:}

\section{Rethinking STEM structures and Standpoints}

"I have frequently been questioned, especially by women, of how I could reconcile family life with a scientific career. Well, it has not been easy”. Marie Curie, 1897-1956

\section{Entering female scientist's world}

The discussion on this research findings are grounded on the female participants standpoints, which stand as testable conclusions to the literature explaining women's under-representation in STEM. Their standpoints have the ability to direct research toward understanding the social structures and relations which shape their lives. These social structures, prevalent in STEM as observed from this research, lend an epistemological frame to what could make 'good science' as it prompts us to see new ways thinking about female scientists' challenges. To do this, I discuss the importance of story-telling, and also look into the 'headwinds' and 'fifth-wheel' metaphors which emerged out of participants stories. I further examine why these metaphors are better alternatives to the 'leaky-pipeline metaphor' and explain the contention that they offer new ways of thinking about how women in STEM 'negotiate' their identities and to what extent they are able to do so. Finally I present why participants' find it important to have more women in STEM and use their lenses to propose ways through which this can be done. 


\section{Story-Telling}

Female participants in this research found it important to share their experiences via personal narratives. Insights to their individual standpoints highlighted their awareness of STEM structures and established grounds for understanding how they negotiate their identities through STEM. More importantly is the fact that all individual stories reflected conflicts which these women encountered and also highlighted different means through which they tried to have them resolved. While only three participants clearly indicated the climax (decisive moments) of their conflicts, all eight participants indicated several means of 'negotiating' conflicts. One means of negotiation common to all of them is determination. The quest to succeed despite the conflicts, keeps them moving on. Fully aware of these conflicts, they give a deaf ear to circumstances which dampen their zeal to excel in the field and stay focused in attaining their objectives.

More still, all female students indicate feeling encouraged to stay focused and determined because of the moral support which they get from their female faculty advisors. They also find female STEM organizations, clubs and magazines to also be a good source of motivation. Given these perspectives, it is noted that female advisors and female STEM organizations have an invaluable role in sustaining these students in STEM. Encouraging such support in other STEM related disciplines could also could also be a useful contribution to more comfortable STEM environments for women.

Besides being determined and supported by female faculty, three out of four female student participants added that their determination was also competition-driven. That is, they expressed the urge to succeed because they want to prove to their male classmates that 
they can equally make good engineers. Their zeal to 'prove' competence suggests that they have at some point been made to feel or understand that they are not 'up to the task'. Even with this conception, they indicate working very hard to prove to the men that they are 'an equal to them'. Female students find the need to work very hard to prove this because as Lynn indicates, they have 'read the culture' which tells them that they don't belong. Whatever the case, this competency-driven urge for success seemingly works for these student participants. On a broader note, it could serve as a source of motivation for female students in STEM. The motivation not to let their abilities go unharnessed, but rather to make their detractors sources of encouragement to develop and utilize their full potential in STEM.

In some cases, some participants resorted to accommodating the conflict. From the student perspective, two of them decided not to react to conflicts which affected them because they believed it was not intentional. Although they admit feeling offended by the situation, they chose not to take it personally. Two faculty on the other hand, indicate accommodating these conflicts because they have gotten used to it. While it is a possibility that the conflicts which these student participants' face could actually be unintentional acts by their male classmates, it is also a possibility that they have not had a wealth of experiences to determine the nature of these conflicts. This is based off Becky's opinion that "sometimes a lot of the young students don't even perceive male-female problems as problems....they are kids and their hormones are aging... ". Again, it is also possible that gender biases are gradually fading away in the present student STEM generation. 
It can thus be argued that participants shared experiences exposed some minute details which could have otherwise been omitted or ignored. Without them, it would have been impossible to know and understand their deep emotional concerns and to make constructive meaning out of their experiences. The different stories and means of negotiation liberate knowledge on both unique and dominant issues which they all face. Given that past experiences serve as better means through which people can make adjustments to future ones, these women's shared experiences inform subsequent ways of implementing positive changes in STEM fields. Their individual standpoints are therefore grounds for improving women's social relations in STEM disciplines. Through these stories, participants connect history to the present and prepare a better future for themselves and others; both present and those yet to come.

\section{Headwinds}

The 'headwinds' metaphor emerged out of participants' stories. It represents the 'extra barriers', not peculiar to men, which these women push through to succeed in STEM. I discuss the dominant headwinds present in this research to highlight some of the difficulty which these participants undergo with the conception that their temporal nature can be negotiated and changed to create a better academic and working climate in STEM. Thus, going beyond this suggests a conscious effort in addressing and re-defining some of these issues to create conducive working environments for women in STEM. Participants' standpoints are a good location from which these 'headwinds' can better be observed. With respect to these views, this research highlights women's difficulty balancing work and 
personal life, gender imbalance in diversity training commitment and the negative feelings that come with these issues.

\section{Work/Personal life balance}

Balancing work and personal life as most participants suggested is not an easy thing to do because there will always have to be 'trade-offs'; that is times when they excelled with academic work and were not able to do same with their personal work and vice versa. Others indicated being unable to manage their personal life with the lot of work to do. Two of these participants indicated having no personal life because they had no children to take care of and one out of the eight indicated being able to balance school and work in her fourth year of college education. Based on their responses, it seemed that a synonym for personal life was taking care of children. This is a 'headwind' which works against women because of the perception that they are constrained by some social conventions. Ruth indicates this when she says that there exists "a more traditional use of women as being home makers and mothers and stuff ...you know... I think it's perpetuated longer in the academic fields than it has in industry. Uhmm...so I think women in academic fields are faced with greater challenges in that regard". Lynn explains this when she adds;

Uhmmm...well you know it's no secret that most societies could... almost... say all societies except the role in the home to be the principle role of women and it's only been in the last maybe been...40 or 50yrs that that's changed to people thinking that that's not a good reason to not educate women and not let them be in STEM so ...I mean women got the right to vote in 1920 in the United States. So if we didn't have the right to vote that's quite clear a attitude about women's capabilities and civil rights frankly. So that has led to it being very difficult.

This goes a long way to contribute to the idea that "when child care is seen as women's work rather than humans' work, there is a clear cost to women, to science, and to society" (Valian 2005, p.214). Hence as Valian argues, "the rigidities of the academic 
career path render it disproportionately difficult for women to have both a family and a successful career, and this trade-off is exacerbated in those STEM fields in which women are most underrepresented" (Ceci et al. 2009, p.13 ). Regardless of this difficulty, participants in this research regard both work and personal life as equally important and so 'negotiate' their way through, by sacrificing other parts of their lives to allocate time for either of these duties as the need arises.

\section{Female Outreach Programs/Imbalance in Diversity Training.}

The underrepresentation of women in STEM fields has led to the implementation of reach-out strategies which, from the students' perspective, has worked favorably well. They were content having female advisors who encouraged their participation in clubs, magazines and female organizations. This poses as a good strategy not only to retain female students in STEM, but also to enable them become deeply involved in STEM activities. It therefore looks promising that female role models are effective in motivating female students to remain in STEM fields. However drawing from faculty perspective, the few women on outreach programs is a direct representation of few female faculty. Despite their minimal presence, they take up the task to promote better academic environments for female students. These women also indicated that men do not help out on female outreach and other related programs. So it becomes evident that, although these programs enhance the experiences of the undergraduate students, it is also at cost to women faculty since there isn't any gender balance. Based on these responses, it seems apt having men take the diversity training and help out on female outreach programs would help in sustaining a female presence in STEM fields. Although 
female students expressed contentment having female faculty support them through the program, it is important to note that both men and women alike are effective in retaining women in STEM (Benjamin et al., 2011). Their presence not only adds numbers to the women on outreach programs, but also enhances an equal gender balance and distribution of labor on the support system.

\section{Male Resistance to Female Authority}

Three of the female faculty highlighted the notion that men resist their authority in the field. Such resistance contributed to feelings of low self-esteem and strive to prove selfworth. Ruth did not feel confident leading a male dominated group of workers because she constantly got the impression that they doubted her competence. It became a challenging task for her to 'prove her worth'. Lynn faces a similar situation when she is given the impression that that only men have the right to dominate meetings. Sarah on her part, suggests having an extra task of taking care of the food for a departmental meeting because she was the only female on the faculty; a possible reason why she believes women have more community work. The different perspectives of male resistance to female authority suggest variations in participants' experiences. It also highlights participants' experiences which they do not appreciate. Looking at the National Academy of Sciences report by Donna Shalala (former secretary of the Department of Health and Human Services) on the issue of the underrepresentation of women in some STEM fields, she insists that

It is not lack of talent, but unintentional biases and outmoded institutional structures that are hindering the access and advancement of women...women are capable of contributing to the nations scientific and engineering enterprise but are impeded in doing so because of gender and racial/ethnic bias and outmoded 'rules' governing academic success. 
Dealing with 'headwinds' may not be an easy task because looking at it at face value, it has to do with boosting morale and building self-esteem which women have lost due to existing STEM structures. Participants admit the presence of these headwinds and work through it with determination to excel in their respective academic fields and workplaces.

\section{Academic Orientation}

The struggles of having a tough time as freshmen in STEM was common to all student participants'. They all indicated having had difficulties grappling with their school work in the first year. Although this can be common with new phases of life, Ella recounts having had this difficulty because some professors did not take her 'seriously'. While at the undergraduate level, Tory who is now a post-doc, also recounted facing difficulties working with 'non-cooperative people.' While Janice had difficulties following the 'general' guidelines which she had been used to in high school, Sandra admits being able to figure out how to make college work only in her senior year. These are some of the struggles which in Sandra's opinion causes some students to drop out of the field. How this can be resolved is crucial to promoting female population in STEM. Thus the need to make freshmen in STEM feel accommodated in their classrooms is vital. This could be considering example-oriented teaching trends, and the consideration that they have a need to adapt to new form of education. More importantly, in the context of female students, teachers should be conscious of the perception that some of the students are already 'pushing through barriers' to succeed in STEM. They should thus be encouraged and not feel they are not taken seriously. 


\section{Women as 'fifth wheels'}

The 'fifth-wheel' metaphor explains participants feeling of isolation, their experience of difference and the reaction of their male peers/colleagues to this difference. It expresses these women's need to 'fit in' to be 'recognized'. Sekaquaptewa (2014) explains this when she says;

When a female undergraduate enters her introductory engineering lecture hall, she may see that $78 \%$ of the seats are occupied by male students, according to current national statistics. Seeing that one's social group is sparsely represented sends a subtle (or perhaps not so subtle) message about whether one belongs in that setting, and raises the specter of stereotypes. , p.2)

Faculty Perspective of the 'fifth-wheel'

All four female faculty expressed this 'specter of stereotypes' as indicated by their 'fifth-wheel' experience. Becky admitted feeling as a 'fifth wheel' because she felt neglected, unrecognized and unappreciated while working with her male colleagues on a group project which in fact, she was supposed to be leading. She was left out of their conversations and when included, found it hard to understand the slangs which they used. She also indicated that men in her department 'whine' and get out of all the work, leaving her with relatively more work than she ought to be doing. She added having felt 'invisible' when she had to teach a class with a 'charismatic male'. Her perception of all this is that, she is not being fully recognized in her duty as a female teacher. Hence, she struggles to 'fit in' to be recognized. Similarly, Ruth indicated taking 'more time' and 'effort' to earn the respect of her colleagues. Her believe that such respect 'would be automatically given to a guy in her position' reflects her perception of difference with her male colleagues. She also suggests being alienated and not recognized while at the industry. That men doubted 
her ability and potential to be their boss is indicative of this. This lack of recognition and feeling of alienation, is also a possible reason why Sarah felt the need to 'talk more' to be 'heard' in her meetings, while Lynn believed she needed to 'talk less' so as not to be 'bossy'. These women's experiences reveal that there exists gender roles which have an effect on how they are perceived and received in STEM fields. Despite their awareness to these gender constructions, they engage diligently and carry out their tasks. It may also be apt to add that their reaction to different situations depends on them as individuals and on the gravity of the issue at hand. While some remain quiet, some speak out and others remain neutral. Their determination to prove their competence in the field stands out as a major motivating factor.

\section{Student Perspective of the 'fifth-wheel'}

Female students also expressed this 'specter of stereotypes' by recounting several challenges which they faced because of their minimal presence in the field. Three out of four students' shared experiences highlighted their representation as 'fifth-wheels'. While it may not be a problem having one woman stand against ten men on interviews as Sandra indicates, it however becomes one when she feels the need to prove her 'worth.' This suggests that she acknowledges a difference which puts her below the standard of her contestants. The lack of belonging and support in such instances could lead to a poor performance on the interview. When Sandra further adds that the expectation of female students to dress in skirts and heels on the field while boys wear baggy pants, it is telling that students have more gender-prescribed roles tagged to them. This is in line with Ella's opinion drawn from popular culture that "girls aren't as good in math and science" and are 
also "not capable of working in STEM fields". Considering that Ella feels she is being "put below" the guys in her classroom; while also making reference to it as a "natural balance which has nothing to do with teacher's influence", she seemingly accepts gender differences. Differences not based on sex but on socialized abilities distributed to gender

roles. In this light, she suggests that women are treated as 'fifth-wheels' in STEM classrooms. Tory on her part, complains of having been the only girl in her under-graduate classroom and faced difficulties working with, 'non-co-operative people'. This is a possible explanation to student's silence or discomfort in asking questions in class. However, depending on the field, area of work, people or spheres of influence, it is possible that only a few percentage of students in STEM get the fifth-wheel' experience. Whatever the case, these minute details of their 'fifth-wheel' experiences need to be considered to enhance better working climates for both students and faculty. Addressing these details will go a long way to boost their morale and make them feel respected and socially accepted.

\section{Headwinds and Fifth Wheels: Alternatives to the Leaky Pipeline metaphor}

The leaky-pipeline metaphor describes the way women drop out of STEM education and related academic workplaces. Scholars like Pawley (2011) and Rosser (1995) insist that it helps 'structural thinking' and 'subsequent policy' making in and around STEM disciplines. Without tossing out the validity of these contentions, I suggest that the 'headwinds' and 'fifth-wheel' metaphors developed from this research are better substitutes to the leaky pipeline metaphor. This is based on the following arguments; 
In a bid to explain the minimal presence of women in STEM, the 'leaky pipeline' metaphor suggests women leak out of STEM at different stages of their academic pathway. This metaphor highlights the existence of leakages in the 'pipes' but does not in any way suggest the causes of them or how they can be fixed. That is, it focuses on the failure of women in STEM without offering reasons for their failure. To fully understand the reason for this failure or causes of these 'leakages' there needs to be a close observation of the problem in the pipeline. In so doing, the focus would be on the women already in the pipeline who have a better insight of the pressures that go on in there, and who can better identify causes of the leaks. If really the underrepresentation of women in STEM is indeed problematic, and if indeed it important that there be more women in STEM, instead of belaboring on metaphors which focus on this issue, I find it more appropriate to make use of those that get in the pipeline to examine the problem. This is not to say that there isn't research going on to trace the origin of female underrepresentation in STEM, but rather to insist that metaphors which support this objective should be used to curb the problem.

Metaphors like the 'headwinds' and 'fifth-wheel' which emerged from this research would be better alternatives to the leaky pipeline metaphor because they focus on the causes of the 'leakages' and not on the 'leaks'. In other words, they pay attention to the issues which women in STEM face in the pipeline and so informs ways through which they can be resolved. While the pipeline implies a passive acceptance of women, the 'headwinds' and 'fifth-wheel' metaphors indicate that women are active; that is they work against these headwinds despite the effects of exhaustion, lack of self-confidence, dampened enthusiasm and paralyzed recognition which they experience. By focusing on 
how women in STEM negotiate their identities, we can better understand their problems and further encourage more women to identify with STEM fields.

Second, the leaky-pipeline metaphor represents the difference between the volumetric flow rates at the pipe's outlet and inlet (Rosser, 1995), without paying attention to where some of 'liquid leaked out' to. That is, it considers women dropping out of STEM fields without looking at the places where they go or what they engage in. Moreover, the idea that 'liquid leaks' out of a pipeline suggests that is no longer useful in the pipe. This connotes a very rigid representation of women in the pipeline that once they leak out, they are no longer useful to the pipeline. It is also important to note that the STEM pipeline is not one linear pipe, but one which has a vast array of disciplines and interrelated work functions. For example, drawing from this research, Ruth who had her undergraduate degree in mechanical engineering, continued with an MBA and is now working on her Ph.D. in mechanical engineering. While she's at it, she doesn't teach engineering classes but find it more interesting to teach engineering students interpersonal skills like 'leadership, teamwork and communication which she believes it is important for them to have. Having worked in industry for an equal length of time as in academia, it would be inappropriate to term her a 'leak' as the leaky pipeline would suggest. She has rather chosen a different pathway in the pipeline.

The information on Ruth's academic pathway was only known after a careful analysis of her choices and the rationale which she presents for them. This was made possible via examining her experiences using the 'headwinds' and 'fifth-wheel' metaphors. Exploring female scientists' lives with these metaphors gives a better picture of what goes 
on in the pipeline, why there are leaks and where women leak out to. In so doing, we also get to appreciate the contributions of women in their respective pathways and not merely represent them as not useful (leaks). Like Ruth, there would be many other women who make very crucial contributions to STEM in pathways not recognized by the standard 'leaky- pipeline' which insists on a progressive and continuous STEM education.

Lastly, the 'leaky-pipeline' metaphor is also not a good way to express the way women feel about STEM structures like the 'headwinds' and 'fifth-wheel' metaphors. It neither takes into consideration women's deep thoughts about their under-representation in STEM fields, nor does it explore their quest to elevate their numbers. This is important because it is only in understanding how these women feel about these structures that creating a more accommodating STEM environment can be guaranteed. Moreover, how these participants' felt about STEM structures was crucial to liberating knowledge on how these structures have evolved over the decades. From this research findings, participants' feelings about some of these structures highlighted their fears, doubts and worries which could have otherwise been ignored. Hence unlike the 'pipe-line' metaphor, the headwinds' and 'fifth-wheel' metaphors reflect the possibility of causing changes to women's plight in STEM. Moreover, they reflect opinions of women still in the pipeline and so present strategies on how these 'leakages' can be sealed. 


\section{Why more women in STEM?}

Women's underrepresentation today results from a complex set of interrelated factors, some of which society could meaningfully address if the focus was placed squarely on them. One key to such success is moving beyond historical issues and confronting current ones. (Ceci \& Williams 2011, p.3157)

Participants in this research find it important that more women should be brought into the field because they imagine themselves to have a unique way of looking at things; a perspective that is different from that of the men. They insist that women possess the ability to catch little details and are more organized than men, who don't take an extra time to look at the different side of things. The opinion that men and women think very differently is brought to suggest that their different points of view are valuable in the field. As Ruth intimates, 'you have to bring in different perspectives and backgrounds and experiences to really get the best ideas and the best solutions. So and that's true of any field not just engineering'. For Valian (2005) "Innovations arise from diverse groups of people with diverse perspectives. It is not that people reason differently as a function of their sex or race, but that they will have somewhat different interests and experiences which in turn give rise to different ideas" (p.215). It therefore still holds that both perspectives are necessary and so more women should be in the field for a better STEM future.

However, steps to include women's perspective can only start when these women's experiences are taken into account in a bid to effect changes that will embrace their presence in STEM. Given that there may be no universal answers to the questions posed by researchers, standpoint theory suggests that "even in the face of these constraints, we 
must nonetheless struggle to understand, to ask our questions, and to listen to each other “(McClish \& Bacon 2002, p.390)

\section{Accelerating the way forward}

Female outreach programs, clubs, discussions and organizations promoted by some of these female participants stood out as an efficient means of encouraging a female presence in STEM. Tory recounted participating on female outreach programs at several schools to encourage women about enrolling in her department. All female students indicated having good advice from their female advisors. Female faculty also served as sources of encouragement as they motivated students be a part of campus clubs and organizations. Sarah expressed her zeal to promote such ventures when she took up the task of organizing discussion groups for female students in her department. This was meant to be a forum where students' difficulties could be shared and resolved. Such groups where women share their stories should be encouraged, so that they get a sense of community life and security. More still, works such as this research should be made available to them so that they can learn from other women's' experiences and also understand that their stories are valued and considered to effect changes. Considering the success of these measures in sustaining student participants in STEM, it could also be made applicable to disciplines other than those represented in this research. Outreach strategies should also be encouraged and used to inform and motivate female students to identify with STEM fields regardless of its structures. 
The need to have more men participate in diversity trainings as some faculty explained, would also enable them to promote outreach programs. Becky insists that men in her department can't be of help despite their long term of office because they 'don't take the diversity training'. She adds that it leaves more work for the few who take the training. Although Lynn believes that men are nonchalant about such roles, she admits that she doesn't understand why it is the case. She further suggests the probability that women get the diversity training is because they attend women's networking lunches, and participate more on campus programs that have to do with women and diversity issues. I note here that these issues are peculiar to this institution but can also serve as a red flag for others.

However, one way through which men can be motivated to participate in campus diversity programs would be to attach general topics to them. By this I mean that the programs should not be tagged 'women's networking' or 'female outreach' because then it makes them feel they do not have to be concerned with it. More general terms like 'STEM networking' or 'student outreach' would attract both male and female faculty. In these meetings, tips on diversity training, outreach programs and issues facing women can be discussed alongside other departmental issues. This is such that the men don't feel the need to refrain from them on the grounds that it is women's issues. In the long run, they would become more aware of the intentional and unintentional biases which women experience and also join the fight to curb it. Although this is not guaranteed, it also men's responsibility to shoulder some of this work. As Lynn insists, men need to be a part of the solution. By attending these meetings, they may learn the importance of serving as role models to encourage female participation in STEM. 


\section{Conclusion}

This research has explored eight women in STEM's awareness of the structures that hinder them from working to their full potential as their male colleagues. It recovered the ways in which women 'negotiate' these structures to thrive in their individual disciplines. The term 'negotiation' was used to represent the various ways through which these women approached these structures. Participants' awareness of these structures was depicted by their personal narratives, which reflect society as still being ingrained in gender stereotypes that work to the detriment of women in STEM. Thus, the extant literature on women's under-representation in STEM, reflected participants' experiences of these stereotypes. Their experiences came alive through grounded theory patterns of coding, categorizing and grouping of their interview responses. To this effect, major insights of this research leaned on the 'fifth- wheel 'and 'headwinds' metaphor which I developed from in-vivo (life-words of participants) codes.

The fifth-wheel metaphor reflected the notion that these women do not only feel 'left-aside' but are also treated differently because of socially constructed reasons. 'Headwinds' on the other hand represented an ongoing effect of stereotypes on women in STEM. I presented the 'headwind' and 'fifth wheel' metaphors as better alternatives to the 'leaky-pipeline' metaphor and also contend that an increase in female students' population is not the only booster to increased female role models, but also requires an active participation and support of men. 


\section{Significance of research}

The findings of this research are significant for a couple of reasons. First, because it uses the lives of participants as the origin of scientific problems, sources of scientific evidence and points from which the validity of claims about women in STEM can be tested. As such, participants' experiences highlight their unique and general encounters with STEM structures and exposes how they 'negotiate' them. Examining these structures is a very vital approach to effecting changes that will benefit women in STEM. Moreover, their ability to negotiate these structures suggests that the structures can be overcome. More importantly, these means of negotiation which has worked for these women could also work for others. Hence, their strategies of 'negotiation' stand to be emulated by women who face similar problems.

This research is also important in that it explores new ways of looking at issues in STEM via the use of grounded theory. With grounded theory, existing issues are explored and developed based on the dominant patterns, which in turn formulate hypothesis. Existing issues in these research were categorized as the 'headwinds' and fifth-wheel' metaphors which have now formed new hypothesis for examining women's experiences in STEM. Testing this hypothesis has created a space for researchers to enter and explore STEM structures to the largest extent possible. Thus, grounded theory served the purpose of closing the gap between theory and empirical research, by making women's standpoints to come alive and inform epistemology. Mindful that the sample size of this research is small, individual standpoints of these women contribute the general literature on women 
in STEM. They also serve as points of departure which expose participants' individual social locations and clarifies partial and distorted understandings of STEM structures.

\section{Suggestions for future work}

Future spaces of research based on these findings would be to look into the possibility of doing the following;

Engage in interview sessions, or conduct an ethnographic research on women in STEM to gain insight to their experiences of 'headwinds' and how they identify as 'fifthwheels'. The goal of this would be to note the 'negotiation' strategies which they employ, so as to inform other women in STEM. This could be encouraged by having women in STEM share their experiences in female conversations and also reading the literature of other women's STEM experiences. They can further promote these initiatives by encouraging a re-writing of this literature based on their own experiences. A long term goal of this would also be to contribute in adding female populations to STEM fields, because it will enhance a more comfortable working climate for women in STEM.

This research could be extended by either quantitative research or by additional qualitative studies that focus on different types of women at different stages in their academic and industrial careers. This will be to examine the correlation of negotiation strategies employed by women in these different STEM pathways.

Considering that the 'headwinds' and fifth-wheel' metaphors are reactive metaphors, that is, they are based off participants' experiences of how they negotiate STEM structures, open spaces for research could be to focus on finding or recovering more

productive metaphors which will better explain both the under-representation of women in 
STEM, and how they are actively working to curb this situation through 'negation' strategies.

A similar kind of interview based research or ethnographic research should also be conducted to understand men's perception of the 'headwinds' which women face. This will also be to question the extent to which their biases (if any) towards women are intentional or out of sheer ignorance. Lastly, it will examine the idea that they feel reluctant to participate in diversity trainings and female outreach programs. Given this possibility, more on this would be to explore how to get them involved on this programs, and eventually support women in eradicating STEM structures. 


\section{Works Cited}

Barker, C. (2003). Cultural studies: Theory and practice. London: Sage.

Barney, G., Strauss, A. L., \& Anzelm. L. (1967). The discovery of grounded theory: Strategies forqualitative research. Chicago: Adline.

Beede, D. N., Julian, T. A., Langdon, D., McKittrick, G., Khan, B., \& Doms, M. E. (2011).

Women in STEM: A gender gap to innovation. Economics and Statistics Administration Issue Brief, 04-11

Campbell, R. (1994). The virtues of feminist empiricism. Hypatia 9(1), 90-115.

Campbell, R., \& Wasco, S. M. (2000). Feminist approaches to social science:

Epistemological and methodological tenets. American Journal of Community Psychology, 28(6), 773-791.

Cantor, N. (2010, February). Women in the academy: Reflections on best practices for survival and success. Address at Washington University, St. Louis, MO.

Code, L. (1991). What can she know?: feminist theory and the construction of knowledge. New York: Cornell University Press.

Ceci, S. J., \& Williams, W. M. (2009). The mathematics of sex: How biology and society conspire to limit talented women and girls. New York: Oxford University Press.

Ceci, S. J., \& Williams, W. M. (2011). Understanding current causes of women's underrepresentation in science. Proceedings of the National Academy of Sciences, 108(8), 3157-3162. 
Ceci, S. J., \& Williams, W. M. (2007). Why aren't more women in science. Top researchers debate the evidence. Washington, DC: American Psychological Association.

Charmaz, K. (2006). Constructing grounded theory: A practical guide through qualitative research. London: Sage Publications.

Charyton, C., Elliott, J. O., Rahman, M. A., Woodard, J. L., \& Dedios, S. (2011). Gender and Science. Women Nobel Laureates in Science, 45(3), 203-214.

Cheryan, S., Siy, J. O., Vichayapai, M., Drury, B. J., \& Kim, S. (2011). Do female and male role models who embody STEM stereotypes hinder women's anticipated success in STEM?. Social Psychological and Personality Science, 2(6), 656-664.

Committee on Science, \& Public Policy (NAS, 2007). Beyond bias and barriers: fulfilling the potential of women in academic science and engineering. National Academies Press.

Cozzens, S. E. (2008). Gender issues in US science and technology policy: equality of what?. Science and engineering ethics, 14(3), 345-356.

Dick, B. (2003, May). AR and grounded theory. In research symposium at the Australian and New Zealand ALARPM/SCIAR conference, Gold Coast, 4(5)

Ecklund, E. H., Lincoln, A. E., \& Tansey, C. (2012). Gender segregation in elite academic science. Gender \& Society, 26(5), 693-717.

Ferguson, K. E. (1985). The feminist case against bureaucracy. Pennsylvania : Temple University Press.

Fox, M. F. (2001). Women, science, and academia Graduate Education and Careers. Gender \& Society, 15(5), 654-666. 
George-Jackson, C. E. (2011). STEM switching: Examining departures of undergraduate women in STEM fields. Journal of Women and Minorities in Science and Engineering, 17(2), 149-171.

Glaser, B. G. (1992). Basics of Grounded Theory Analysis. Emergence versus Forcing. Mill Valley,C.A.: Sociology Press.

Goulding, C. (2002). Grounded theory: A practical guide for Management, Business and Market Researchers. London: Sage Publications.

Harding, S. G. (1991). Whose science? Whose knowledge?: Thinking from women's lives. Ithaca N.Y.: Cornell University Press.

Hartsock, N.C.M. (1983). 'The Feminist Standpoint: Developing the Ground for a Specifically Feminist Historical Materialism', in S. Harding \& M. B. Hintikka (eds), Discovering Reality: Boston: D. Reidel, 283-310

Hundleby, C. (2011). Feminist empiricism. In Sharlene Nagy Hesse-Biber (ed) Handbook of feminist research: Theory and praxis. (pp. 28-39). Boston: Sage Publications

Landivar, L. C. (2013). Disparities in STEM employment by sex, race, and Hispanic origin. Education Review, 29(6), 911-922.

Leetaru, K. (2010). A new look at the institutional impact on women in postsecondary engineering education 1966-2007. Journal of Women and Minorities in Science and Engineering, 16(2), 177-197.

Lundgren, E. (1995). Feminist Theory and Violent Empiricism, Aldershot: Avebury Mason, M. A., \& Ekman, E. M. (2007). Mothers on the fast track: How a new generation can balance family and careers. Oxford University Press. 
Mavriplis, C., Heller, R., Beil, C., Dam, K., Yassinskaya, N., Shaw, M., \& Sorensen, C. (2010).

Mind the gap: Women in STEM career breaks. Journal of technology management \& innovation, 5(1), 140-151.

McClish, G., \& Bacon, J. (2002). "Telling the story her own way": The role of feminist standpoint theory in rhetorical studies. Rhetoric Society Quarterly, 32(2), 27-55.

National Science Board (NSB). 2010. Science and Engineering Indicators 2010. Arlington, VA: National Science Board.

Nelson, L. (2010). Who knows: From Quine to a Feminist Empiricism. Philadelphia: Temple University Press.

Ong, M., Wright, C., Espinosa, L. L., \& Orfield, G. (2011). Inside the double bind: A synthesis of empirical research on undergraduate and graduate women of color in science, technology, engineering, and mathematics. Harvard Educational Review, 81(2), 17-209.

Paludi, M. A., \& Bauer, W. D. (1983). Goldberg revisited: What's in an author's name. Sex Roles, 9(3), 387-390.

Pawley, A. L., \& Hoegh, J. (2011, June). Exploding pipelines: Mythological metaphors structuring diversity-oriented engineering education research agendas. In American Society for Engineering Education Annual Conference, Vancouver, BC, Canada.

Poggio, B. (2006) Outline of a theory of gender practices. Gender, Work \& Organization, 13(3), 225-33. 
Richman, L. S., vanDellen, M., \& Wood, W. (2011). How women cope: Being a numerical minority in a male-dominated profession. Journal of Social Issues, 67(3), 492-509.

Rosser, S. V. (1995). Teaching the Majority: Breaking the Gender Barrier in Science, Mathematics, and Engineering. Teachers College Press, Columbia University, New York

Rossiter, M. W. (1982). Women scientists in America: Struggles and strategies to 1940 (1). Baltimore: JHU Press.

Schiebinger, Londa (1999). Has Feminism Changed Science? Cambridge: Harvard University Press.

Sekaquaptewa, D. Calling for a Change in the STEM Climate. Association for Psychological science. Observer Vol.27, No.5 May/June, 2014

Sewell Jr, W. H. (1992). A theory of structure: Duality, agency, and transformation. American journal of sociology, 1-29.

Seymour, E. (1995). The loss of women from science, mathematics, and engineering undergraduate majors: An explanatory account. Science Education, 79(4), 437-473.

Sonnert, G., Fox, M. \& Adkins, K. (2007). Undergraduate women in science and engineering: Effects of faculty, fields, and institutions over time. Social Science Quarterly, 88(5),1333- 1356.

Steinpreis, R. E., Anders, K. A., \& Ritzke, D. (1999). The impact of gender on the review of the curricula vitae of job applicants and tenure candidates: A national empirical study. Sex roles, 41(7/8), 509-528. 
Strauss, A., \& Corbin, J. (1998). Basics of Qualitative Research: Techniques and Procedures for Developing Grounded Theory ( $2^{\text {nd }}$ ed). Thousand Oaks, C.A.: Sage Publications

Swigonski, M. E. (1994). The logic of feminist standpoint theory for social work research. Social Work, 39(4), 387-393.

Symonds, M. 2007. "Perspectives: Quantity, Quality and Equality.” New Scientist, 195: 2611.

Tacsir, Ezequiel, Matteo Grazzi, and Rafael Castillo. (2014). Women in science and technology: what does the literature Say?. Inter-American Development Bank, 132

Tuana, N. (1995). The values of science: Empiricism from a feminist perspective. Synthese, 104(3), 441-461.

United States National Academy of Sciences (NAS). 2007. Beyond Bias and Barriers: Fulfilling the Potential of Women in Academic Science and Engineering. Washington, DC: National Academies Press.

Van Anders, S. M. (2004). Why the academic pipeline leaks: Fewer men than women perceive barriers to becoming professors. Sex roles, 51(9/10), 511-521.

Van Den Brink, M., \& Stobbe, L. (2009). Doing gender in academic education: The paradox of visibility. Gender, Work \& Organization, 16(4), 451-470.

Valian, V. (2005). Beyond gender schemas: Improving the advancement of women in academia. Hypatia, 20(3), 198-213. 
Valian, V. (1998). Why so slow? The Advancement of Women. Cambridge, MA: MIT Press, 280

Weinberger, C. J. (2005). Is the science and engineering workforce drawn from the far upper tail of the math ability distribution. Unpublished paper

Wendt, R. F. (1995). Women in positions of service: The politicized body.Communication Studies, 46(3-4), 276-296.

Wold, A., \& Wennerås, C. (1997). Nepotism and sexism in peer review. Nature, 387(6631), 341- 343 .

Wuhib, F. W., \& Dotger, S. (2014, March). Why so few women in STEM: The role of social coping. In Integrated STEM Education Conference (ISEC), 2014 IEEE (pp. 1-7). IEEE.

Zuckerman, H. (1991). The careers of men and women scientists: A review of current research. In: H. Zuckerman, J. R. Cole, and J.T. Bruer (ed) The Outer Circle: Women in the Scientific Community. p 27. W.W. Norton: New York. 


\section{Appendix A Interview Questions}

\section{Student Interview Questions}

\section{Section A.}

\section{Professional Background}

In this section I wish to get insight about your academic background and reasons for your presence in this field.

1. What is your department and major?

2. What is your level of education?

3. Why did you choose to study in this field?

4. Why would you consider yourself a successful Scientist/Engineering student?

\section{Section B}

\section{Structure in STEM}

In Section B, I seek to find out the male-female ratio of gender division in your department and get to know your perception of this structure.

1. How many boys and girls are there in your department?

2. What do you think is being done to maintain or enhance gender equality in your department?

a) How successful has this been?

b) How is the department contributing towards this?

c) In your opinion what are some of the hindrances to this?

3. Do you think there are fewer girls in STEM?

-If yes, why do you think fewer girls are attracted to STEM than other departments?

-If no, what are your reasons?

4. Do you find it important that girls should be brought into the field? Why/why not?

\section{Section C}

\section{Enacting Identities}

In Section C, I intend to find out how the socialization of gender influences your representation as a student in STEM.

1. How is work distributed between you and your peers? 
-How would you describe your team work relationship with your peers?

2. How often do you feel comfortable asking questions in class? Why?

3. What roles are you asked to take- leadership or supportive? -Why do you feel inclined to accept either of this roles?

4. What is your relationship with faculty like? -Why do you feel challenged or supported?

5. How do you balance your school work and personal life?

6. What are the greatest challenges and rewards you've had in your academics/discipline?

The rest of the questions are based on one of the key findings by Hill, C., Corbett, C., \& St Rose, A. (2010) in Why So Few? Women in Science, Technology, Engineering, and Mathematics.

"The achievement gap between male and female students in science, technology, engineering, and math (STEM) is steadily closing, but cultural biases and institutional barriers still hinder the advancement of girls and women in these fields."

7. Do you share this point of view?

8. How do you think the following supports/hinders the advancement of girls and women in these fields?

a) Cultural biases

b) Institutional biases

c) Do you feel that these biases hinder or enhance your relationship with your male peers?

9. What is your advice to aspiring female students in STEM? 


\section{Faculty Interview Questions}

\section{Section A.}

\section{Professional Background}

In this section I wish to get insight about your academic background and reasons for your presence in this field.

1. What is your profession or field?

2. How long have you worked in this profession?

3. Why did you choose to work in this field?

4. What other fields would you admire and why?

5. Why would you consider yourself a successful Scientist/Engineer?

\section{Section B}

\section{Structure in STEM}

In Section B, I seek to find out the male-female ratio of gender division in your department and get to know your perception of this structure.

6. How many faculty are full professors, associates, and assistants?

a) How many women and how many men occupy each of these categories?

7. What do you think is being done to maintain or enhance gender equality?

d) How successful has this been?

e) How is the department contributing towards this?

f) In your opinion what are some of the hindrances to this?

8. Do you think there are fewer women in STEM?

-If yes, why do you think fewer women are attracted to STEM than other departments?

-If no, what are your reasons?

9. Do you find it important that women should be brought into the field? Why/why not? 


\section{Section C}

\section{Enacting Identities}

In Section C, I intend to find out how the socialization of gender influences your representation as a woman working in STEM.

10. Has the STEM field influenced your working ability as a woman?

a) How is work distributed between you and your colleagues?

b) How would you describe your working relationship them?

11. How do you balance your work and personal life?

12. What are the greatest challenges and greatest rewards you've faced in your professional career?

13. How much research funding have you had in the past three years?

-How would you compare your research funding to that of your colleagues?

-Do your female colleagues get the same funding as you?

-Would you say this level of funding is comparable to that of your male colleagues? why/why not?

The rest of the questions are based on one of the key findings by Hill, C., Corbett, C., \& St Rose, A. (2010) in Why So Few? Women in Science, Technology, Engineering, and Mathematics.

"The achievement gap between male and female students in science, technology, engineering, and math (STEM) is steadily closing, but cultural biases and institutional barriers still hinder the advancement of girls and women in these fields."

14. Do you share this point of view?

15. How do you think the following supports/hinders the advancement of girls and women in these fields?

a) Cultural biases

b) Institutional biases

c) Do you feel that these biases hinder or enhance your relationship with your male colleagues?

16. What is your advice to aspiring female students in STEM? 


\section{Appendix B}

Consent Forms

\section{Consent to participate in Interview}

\section{Faculty Consent Form}

You have been asked to participate in an interview conducted by Sidouane Patcha Lum from the Humanities department of Michigan Technological University for her MA research thesis (HU 5990) titled Gender Construction in STEM: A peep into the 'leaky pipeline' metaphor. This research is supervised by Dr. Anne Brady, Michigan Technological University. Your participation is entirely voluntary. Please read the information below and ask questions about anything you do not understand before the interview is conducted.

\section{Purpose of the Interview}

The purpose of this interview is to find out to what extent female professors in STEM both maintain and enact their identities as women who are not limited by the bounds of a 'male centered' field. This is considering that several scholars have taken note of women's underrepresentation in STEM for reasons such as differences in girls' and boys' attitudes towards science in the early secondary school years, lack of female interest, biological differences and income disparity.

REASON FOR INVITATION: You have been selected for this interview based on your long term experience and contributions as a female professor in STEM. The insights of your shared experiences will be very useful for this research.

PROCEDURES: This interview will be conducted with the use of an audio recorder and notes will also be taken. You will be asked both prepared and spontaneous follow-up questions. If recorded, precautions will be taken to preserve confidentiality (see below).

However, you also reserve the right to decline being recorded. The interview will last for $35 \mathrm{mins}$. There are no costs involved.

\section{PRIVACY and CONFIDENTIALITY STATEMENT:}

Your identity will not be shared with anyone other than the research team. All interview data will be stored in a secured drawer with a lock for a minimum of 3yrs. Any transcriptions of all or parts 
of the interview will also be stored on a password protected computer that is only accessible to the PI. Any information that is obtained in connection with this study and that can be identified with you will remain confidential and will be disclosed only with your permission or as required by law. Confidentiality will be maintained with the use pseudonyms.

RISK: There are no known risks involved for participating in this research. In the event of physical and/or mental injury resulting from participation in this research project,

Michigan Technological University does not provide any medical, hospitalization or other insurance for participants in this research study, nor will Michigan Technological University provide any medical treatment or compensation for any injury sustained as a result of participation in this research study, except as required by law.

POTENTIAL BENEFITS: You may not benefit directly from participating in this interview. Your participation will help the interviewer to learn more about women's experiences in STEM, compare with existing data and create new findings that will be beneficial to the women in STEM, women in academia and also create room for further research

VOLUNTARY PARTICIPATORY STATEMENT: Your participation in this research study is completely voluntary. You may choose to decline to answer any questions as you wish without consequences of any kind. There is no penalty if you stop the interview or if you request that the audio recorder be turned off. Withdrawal from this interview will have no effect on you.

RESEARCH STUDY RESULTS: If you wish to learn about the results of this research study you may request that information by contacting: Sidouane Patcha-Lum, 9063704289, plsidoua@mtu.edu or Dr. Anne Brady, Department of Humanities, Michigan Technological University, Houghton MI,49931-1295, tel:(906) 487-2066, Email: mabrady@ mtu.edu

HUMAN SUBJECT RIGHTS: The Michigan Tech Institutional Review Board has reviewed my request to conduct this project. If you have any concerns about your rights in this study, please contact the office of Compliance, Integrity, and Safety at 906-487-2902 or email $\underline{\text { IRB @ mtu.edu }}$

AGREEMENT TO PARTICIPATE: By signing this consent form below, you are stating the following: 
- The details of this research study have been explained to me including what I am being asked to do and the anticipated risks and benefits:

- I have had an opportunity to have my questions answered

- I am voluntarily agreeing to participate in the research as described on this form

- I have been given a copy of this document for my records

- I may ask more questions or stop participating at any time without penalty.

Please check the box which applies to you and sign below.

I agree to participate and be recorded

I agree to participate but I do not agree to be recorded

Print name:

Signature:

Date: 


\section{Student Consent Form}

\section{Consent to participate in Interview}

You have been asked to participate in an interview conducted by Sidouane Patcha Lum from the Humanities department of Michigan Technological University for her MA research thesis (HU 5990) titled Gender Construction in STEM: A peep into the 'leaky pipeline' metaphor. This research is supervised by Dr. Anne Brady, Michigan Technological University. Your participation is entirely voluntary. Please read the information below and ask questions about anything you do not understand before the interview is conducted.

\section{Purpose of the Interview}

The purpose of this interview is to find out to what extent female students in STEM both maintain and enact their identities as women who are not limited by the bounds of a 'male centered' field. This is considering that several scholars have taken note of girl's underrepresentation in STEM for reasons such as differences in girls' and boys' attitudes towards science in the early secondary school years, lack of female interest and biological differences.

REASON FOR INVITATION: You have been selected for this interview based on your long term experience as a senior in STEM. The insights of your shared experiences will be very useful for this research.

PROCEDURES: This interview will be conducted with the use of an audio recorder and notes will also be taken. You will be asked both prepared and spontaneous follow-up questions. If recorded, precautions will be taken to preserve confidentiality (see below).

However, you also reserve the right to decline being recorded. The interview will last for $35 \mathrm{mins}$. There are no costs involved.

\section{PRIVACY and CONFIDENTIALITY STATEMENT:}

Your identity will not be shared with anyone other than the research team. All interview data will be stored in a secured drawer with a lock for a minimum of 3yrs. Any transcriptions of all or parts of the interview will also be stored on a password protected computer that is only accessible to the PI. Information collected will not be shared with professors and will have no effect on your class 
grade or standing. Any information that is obtained in connection with this study and that can be identified with you will remain confidential and will be disclosed only with your permission or as required by law. Confidentiality will be maintained with the use pseudonyms.

RISK: There are no known risks involved for participating in this research. In the event of physical and/or mental injury resulting from participation in this research project,

Michigan Technological University does not provide any medical, hospitalization or other insurance for participants in this research study, nor will Michigan Technological University provide any medical treatment or compensation for any injury sustained as a result of participation in this research study, except as required by law.

POTENTIAL BENEFITS: You may not benefit directly from participating in this interview. Your participation will help the interviewer to learn more about students experiences in STEM, compare with existing data and create new findings that will be beneficial to present and future students in STEM, women in academia and also create room for further research.

VOLUNTARY PARTICIPATORY STATEMENT: Your participation in this research study is completely voluntary. You may choose to decline to answer any questions as you wish without consequences of any kind. There is no penalty if you stop the interview or if you request that the audio recorder be turned off. Withdrawal from this interview will have no effect on your class grade or class standing.

RESEARCH STUDY RESULTS: If you wish to learn about the results of this research study you may request that information by contacting: Sidouane Patcha-Lum, 9063704289, plsidoua@mtu.edu or Dr. Anne Brady, Department of Humanities, Michigan Technological University, Houghton MI,49931-1295, tel:(906) 487-2066, Email: mabrady@ mtu.edu

HUMAN SUBJECT RIGHTS: The Michigan Tech Institutional Review Board has reviewed my request to conduct this project. If you have any concerns about your rights in this study, please contact the office of Compliance, Integrity, and Safety at 906-487-2902 or email $\underline{\text { IRB@ @mtu.edu }}$

AGREEMENT TO PARTICIPATE: By signing this consent form below, you are stating the following: 
- The details of this research study have been explained to me including what I am being asked to do and the anticipated risks and benefits:

- I have had an opportunity to have my questions answered

- I am voluntarily agreeing to participate in the research as described on this form

- I have been given a copy of this document for my records

- I may ask more questions or stop participating at any time without penalty.

Please check the box which applies to you and sign below.

I agree to participate and be recorded

I agree to participate but I do not agree to be recorded

Print name:

Signature:

Date: 


\section{Appendix C \\ Participant Bibliographical Sketches \\ Faculty Profiles}

Female faculty profiles provide information on their academic backgrounds, disciplines and the reason why they chose to be in their respective fields. It also highlights some of their contributions to the field.

\section{Ruth}

Ruth had her undergraduate degree in mechanical engineering. She continued with a Master's in Business Administration (MBA) and is now working towards obtaining a $\mathrm{PhD}$ in mechanical engineering. She worked in Industry for 15years and has also been working in academia for 15years. She got very interested in engineering when she started working for an automotive industry. Ruth is presently working at a college organization affiliated to a Midwestern research institution. Her focus is to help engineering students' develop leadership, teamwork and inter-personal skills. She also finds it important to increase diversity amongst the programs and so her organization accommodates students from other fields. Ruth has successfully managed leadership positions in industry and is now making equal contributions through her organization, to the mechanical engineering department.

Lynn

Lynn has been a professor of chemical engineering for 25 years at a Midwestern research institution in the United States of America. Her interest in this fields stems from her love for math and chemistry back in high school. She was also encouraged to get into engineering by her dad who was an engineer. 
She enjoys reading and improving her classes. She remains ever willing to make useful contributions to the chemical engineering department.

\section{Becky}

Having had several other professions, Becky has also been working in academia for a period of 40years. She is presently professor of biology at a Midwestern university. Becky started out as an art major and moved to biological sciences after having a part-time job in a research aquarium. This heightened her love for scientific questioning and being with fish. Becky has been successful in mentoring graduate students and making significant contributions to her department.

\section{Sarah}

Sarah is an associate lecturer of Astro-Physics at a Midwestern university. She has been working in the field for about 15years. She got her PhD in Germany, after working on an OPAL (Omni purpose apparatus) experiment. This experiment measured particle collisions at the LEP (large electron positron) storage range. As a research assistant professor, she also worked in a field that engaged in an ultra-energy cosmic rate research. Back in high school, Sarah was interested in psychology, philosophy and physics. She ended up in physics because of her interest in making applicable the things that she learned. Out of her interest in fundamental questioning, she has been very much involved in experimental physics, where she focuses on building, designing and running her own experiments. She 
is fulfilled doing what she loves and has made successful contributions to physics through her research expertise and experiments.

\section{Student Profiles}

I present student academic backgrounds and indicate the reasons why they chose to be in their respective disciplines.

\section{Ella}

Ella was drawn to engineering because of the idea that it is a mixture of math and science. She loved biology and medical professions, but did not want to be a nurse or doctor. As such, she settled for Medical engineering where she is now a senior. Ella finds this field interesting because it if full of new discovery and new equipment in medical technology. She is also very determined to succeed in the field of engineering.

\section{Janice}

Having started her education in fresh water studies, Janice moved to civil engineering because she understood math and could read meaning into structures. She was also encouraged to do so because her dad is an engineer. However, she still maintains her fresh water studies in the field of engineering because her focus is on a water resource pathway. Janice loves engineering because it makes her think out the box, and employ her problem solving abilities. She has been successful working on internships and co-ops. She is presently doing her undergraduate research in the water resources department. 


\section{Sandra}

Sandra is a senior student in environmental engineering at a Midwestern university. She was drawn to this field because of her love for out-door work. She is very involved with campus activities and also very determined to excel in her field.

\section{Tory}

Tory got her PHD in Astro-Physics in 2011 and is now a post-doc at a Midwestern university. She got interested in this field out of her zeal to be an astronaut. Her curiosity in astronomy led her to take astronomy cases, which eventually put her in Astro-Physics. She writes proposals and travels regularly to support her departmental research goals. 


\section{Appendix D \\ Transcribed Texts}

In this section, I acknowledge participants' voices as the most useful contributions to this research findings. I present portions their individual responses which emerged out of the original research questions:

- How they negotiate STEM structures

- The extent to which they are able to do so

To make the information more easily accessible, I have categorized their responses under the following key categories: conflicts, climax, resolution, headwinds and fifth-wheel. Along the margins, I mark participant's voices with key quotes used in the text to facilitate identification and reveal the context within which this it was used.

\section{Conflicts}

Intra-personal and Ideological conflicts.

\section{Lynn}

Whatever the women do is always reported back in the context of the womanly things

Well again from my reading uhmmm...when presented with two resumes, one with a woman's name, one with a man's name, there's a decrement that the woman's resume is rated lower. When asked what salary to give to two people with identical records, they do these studies and the woman is given the lower one. When women are interviewed and they follow a script and they do these psychological studies and they do the same thing with the men. Whatever the women do is always reported back in the context of the womanly things you know like you know...she was too harsh, she was too brash whereas the man with the same words was a leader and all those annoying things... and headed the table issue...you know when they ask her subjects whose the head of this meeting if they saw a man at the head of the table it's the man at the head of the table, if they saw a woman at the head of the 
table it's the woman at the head of the table. But if it's a mixture of men and women, and there's a man at the head of the table, then he's the head of the meeting but if it's a mixture of men and women, there's a woman at the head of the table, half the time they pick a man seated somewhere else. So all of these social science studies show that we are not, I am not in the same world as my male colleagues at all and I feel it every day. I feel it every meeting when I speak, I have to consider how my speech is being received... But I have to think how is it gonna look because bossy big mouth Lynn is gonna be talking and dominating the meeting.

\section{Sarah}

We may be over talked easily I think

we have to work a little harder to be heard

I noticed with Vera and I when we hold meetings 30 of our colleagues don't help and I noticed that she and I don't talk. We use a chat window on a computer rather than talk. For example when I run a meeting it's not like people talk over me when I run a meeting I run a meeting and that's clear. But in these captions you know we may be over talked easily I think we have to work a little harder to be heard.

\section{Ruth}

He had more confidence

In me than I had in myself

I had a boss at one point in my career when I was working with automotive who...I think truly had more confidence in me than I had in myself and so he will push me to take on bigger challenges even when I thought I wasn't ready for most of them...you know...he was very supportive, and he would convince me I could do it so...he would promote me into positions that I was like' I'm not ready for this' but he saw that I was.

\section{Conflict of power}

\section{Lynn}

It's easier to drop out if

you are a woman than if you are man.

There's nothing more satisfying like being a mum and we need more moms like you to volunteer in the schools and to make sure that society works well all through... all the things my mother did...all through but if a man at 35 when his kids are young suddenly says this is ridiculous I'm gonna stay at home with the kids and my wife is gonna stay in her job, he's gonna get...he's gonna spend a lifetime with that wind in his face you know ... when people say hey what do you 
do bill? and he's gonna say I stay at home with the kids for 20yrs and they are gonna feel like what mental illness do you have you know? What are you covering up? Are you alcoholic are you? Is that a code for I was in prison? You know he's gonna get all kinds of negative push back and she's not. She's just gonna be... and then when she goes to dinner parties... and people say what do you do and she goes the kid's fine and on with life you know. So it's easier to drop out if you are a woman than if you are man. And so the people who don't drop out are the ones at the top of the distribution who are like...I will not be happy you know, it's easier to drop out.

\section{Sandra}

I had a guy that would be done with whatever he was doing...he'd come and take over.. from me

There's nothing more satisfying like being a mum and we need more moms like you to volunteer in the schools and to make sure that society works well all through... all the things my mother did...all through but if a man at 35 when his kids are young suddenly says this is ridiculous I'm gonna stay at home with the kids and my wife is gonna stay in her job, he's gonna get...he's gonna spend a lifetime with that wind in his face you know ... when people say hey what do you do bill? and he's gonna say I stay at home with the kids for 20yrs and they are gonna feel like what mental illness do you have you know? What are you covering up? Are you alcoholic are you? Is that a code for I was in prison? You know he's gonna get all kinds of negative push back and she's not. She's just gonna be... and then when she goes to dinner parties... and people say what do you do and she goes the kid's fine and on with life you know. So it's easier to drop out if you are a woman than if you are man. And so the people who don't drop out are the ones at the top of the distribution who are like...I will not be happy you know, it's easier to drop out.

\section{Tory}

sometimes people don't

treat you as an equal person

If someone was discriminating against you know you just have to... at least have the topic out but if you think about it right... there are gonna be options... staying in the field or sometimes people don't treat you as an equal person so then you just go out and get another street job then you earn money and you go home... unless you really want to stay in academia you're not gonna be constantly fighting these doubts, you'd just leave and that's why...you know there are these obstacles after obstacles then all of a sudden it seems like they even get so much further ideas why ...you know why would I have to be here? 


\section{Ideological and Psychological Conflicts}

\section{Lynn}

Women don't persist in STEM fields

because they read the culture and

the culture tells them they don't belong.

Frankly I think women don't persist in STEM fields because they read the culture and the culture tells them they don't belong. They read the culture... the culture tells them that they are supposed to be pretty, they are meant to be...ehmm pleasing they are meant to be sociable and sweet and differential and soft spoken and they read that and if that at all matches with their self-image, they probably do it, probably hardly...If it's a mismatch, where that doesn't seem to make sense to them, then they'll persist through those cultural signals and then they'll face that headwind continuously. I think that the message to women is relentless you know. It's depressing because you can brush it aside and ignore it but off course you are not perfect and so you have flaws and so when it the message from the culture matches something is true. Like oh this is hard for you, you are not really that good at something then the two things amplify and then suddenly you say ohhh it's all true. I don't belong.

\section{Climax}

\section{Lynn}

No one has ever asked me to talk to a group of men though

But maybe I should...

I'm not sure I'd tell them anything.... (Long silence) Because it might be better to pretend that it's not a problem for them. Actually I feel like I would wanna say something to the men. I'd have to get the women out of the room so they don't have to hear it. I will tell the men that this schema exists, and that they are getting an unearned advantage... by being male and right now when you are a freshman and a sophomore, you're gonna say the men and the women are equal in fact the smartest people in my class are women. Yes they are... The smartest women in the class in fact are gonna be women. Because they are people who have been pushing up already against the headwind and they are better than the men. And you are gonna think that this gender problem has been solved...well let me tell you men that we taught that was true 30yrs ago and the women in the 70's thought it was true 15yrs before that and it wasn't true either time and it's not true now. So when you wake up in mid-career and some of the women are gone, you're gonna remember what 
I'm telling you right now and I want you to believe that this really exists and I want you to be a part of the solution. Don't wait till you have daughters and it pisses you off that your daughter is discriminated against. Be part of the solution now. No one has ever asked me to talk to a group of men though. But maybe I should...Some will remember because they are not doing it deliberately. But the men are never gonna hear it unless you sit them down. the positive thing about talking to a room full of men is that some fraction will like take the data seriously and it'll lock in somewhere and when they are in the room and a decision is being made, they might go wait a second and that might make a change. We need more people doing that.

\section{Becky}

I yelled at all of them and

he is in the river with the guys

and he doesn't see it

I think sometimes women, young women allow themselves to be sort of taken care of and other times men just assume the role of men ... uhm...we see it like when we take groups of students out in the field and we have field work to do and a lot of times it'll be the guys that grab the gear and jump in the water and the women stand on the shore with a note book and u know...I'll have to yell at them and say ok "we'll do this for five minutes"... but then you'll all switching and then the women are in the river with the gear in ... but I think it's so ingrained in a lot of people that those are their roles and they just instantly assume them ...I think that's everywhere ... I think that's discouraged everywhere one of the things I think that is a hindrance is that men don't realize what's going on.....and that person who I used to teach was on that field trip when we took the kids out to the river and all the men jumped in with all the gear.. And all the women are standing at the shore and I yelled at all of them and he is in the river with the guys and he doesn't see it... you know and so if your colleague doesn't help and see it and involve and engage .... and so if we are not working at fixing that and demonstrating that in the classes then how will the women and the men in those classes see that?

\section{Ella}

I really considered dropping

and doing something like nursing

I think during my first year I was taking some classes that were tough for me... I think the mechanical engineering class and a couple more. I really considered dropping and doing something like nursing which I felt was relatively easier. Also getting involved in it was hard ... as a transfer student I had to meet new people and that was tough. But now its fine I feel more involved in activities in school.

\section{Tory}

I'm ok with not being the best of the best 
Sometimes people aren't really happy they are always like competing...I'm ok to take a step back you know and still enjoy what I'm doing but I still make contributions to ... you know our field in physics and I don't need to be caught up competing.... I don't wanna spend $120 \mathrm{hrs}$ working and sometimes that's what's needed if you wanna be at the very very top and I think throughout the years I've come to realize that I've come to realize that I'm ok with not being the best of the best. I mean if it means I have to sacrifice family and just you know... just normal life... I dunno I am happy to take a step back and say ok... as long as I am making contributions and I'm useful I would still like to have fun.

\section{Resolution}

\section{Determination}

\section{Ruth}

If you love doing it don't let anything in your way

I would say to any student focus on doing what you are all doing you know, uhmm... and then it becomes easy to kind of push through those barriers, but if you don't really love it, then it just becomes this huge burden. You know... and then you know it's not fun, it's stressful and all those things. So I think the first step is...to find what you love doing no matter what it does and then just persist you know...whatever barriers exist in that field...in that area. If you love doing it don't let anything in your way. So some things will come easier than others you know but uhmmm... if you love building things and tinkering with things and envision yourself working as a mechanical engineer, you know... there is no reason any other is gonna stop this to get in your way, unless you let it.

\section{Sarah}

To quit and say they will

not make it is wrong

They should stay with-it if they like it and that they should not quit if they think they are not good enough. They might not be good enough but to quit and say they will not make it is wrong. I was about to quit physics and someone said after my PhD... I had a good friend he advised me about it.

\section{Sandra}

Work hard and be dedicated and have motivation and you know and not be scared to ask questions 
I would say that...you know I definitely would like to support women or girls who think that they are interested in engineering ...I want that I think that it's good for them to come and work hard and be dedicated and have motivation and you know and not be scared to ask questions and not be scared to make yourself separated from other people because ultimately when you do go to get a job, and you do... you know apply for research or graduate school you...only so many people get it... right so I'd say if you start organizing yourself early and bring something different to the table earlier in your college career that ... you know ... you will stand out when you graduate

\section{Ella}

I will tell them not to let the guys intimidate you

I will encourage them...I will tell them not to let the guys intimidate you... don't let them bother you... don't think of them as different from yourself. You might not understand some things like they do but ask questions. I will tell them to stick with it

\section{Tory}

There's just always people that are negative and you shouldn't let them affect you

I would say you could do whatever you want to do, whatever you want to study.. if you find enjoyment out of it and you really like it you should go for it and there will always be... there's just always people that are negative and you shouldn't let them affect you...I think that applies to everything in life ... yeah..

\section{Competency}

\section{Janice}

I have to prove to them

that I can be an engineer

Because I really want to really be an environmental engineer. I have a lot of determination, I am also very prideful. So I considered switching majors and then moving back home but I ...as I said I was in robotics with mostly males and I was very much like no I have to prove to them that I can be an engineer and that I can do this ..uhmm and I don't talk to any of them anymore but to me it's still I have to prove to them that I can do this... whether they'll know or not. 


\section{Tory}

I want to show them that if you

want to do it, you can

I want to show them that if you want to do it, you can, that it's not just men that do physics. So much like it's not just men that can be mechanics...you know what if you are really interested you can figure it out yourself and you know. There are people out there who can help you.

\section{Accommodation}

\section{Becky}

I've been waiting till some

of these sluggards retire

You know it amazes me one of those smart CEO says well just wait until they retire, you know it's like my whole life here I've been waiting till some of these sluggards retire and I'm still waiting and I'm nearing retirement so...I dunno

\section{Sarah}

It's a feeling you need to get used to and that you always think other people are better than you

I have seen many people leaving the field saying they work too many long hours, not enough money, recognition and I always feel I'm not good enough. It's a feeling you need to get used to and that you always think other people are better than you. But that's by the way true for any field. Some of my friends left physics and they say it's not as bad as it was in physics.

\section{Tory}

I don't take things personally

I don't take things personally despite when you know...if ...I've heard people that pass on insults to each other and they still are not working that....and I also realized that sometimes they don't mean it... because sometimes they apologize because they didn't realize how terrible it sounded when they talked to that person... and I've come to a conclusion that sometimes scientists are just cruel with when they say things...

\section{Headwinds}

\section{Imbalance in diversity training commitment}




\section{Lynn}

"we're not at the numbers yet where we...

have to direct all the recruitment towards the women.

We're not at the numbers yet where we can start saying that we have you know...equal men and women and we don't have to direct all the recruitment towards the women.

Men "always be like...oh...Lets' send the women to the women's ...you know..."

\section{Ruth}

It's just a portion of women who are

motivated by this math and science...

Lots of girls go to nursing or some kind of medical degree or they go for humanities or social science I think just because that's what they interested in, it is just a portion of women who are motivated by this math and science you know...

\section{Becky}

men in this department ...

don't take the diversity training

There are men in this department that have been here for years, don't take the diversity training and so therefore can't take sit on the committee, can't do service and so... get some done...there's less that do take the training and our ....that's one of the thing

\section{Sarah}

If you have five people giving talks and four of them are women you know that probably those four are the only four in the department

If you have five people giving talks and four of them are women you know that probably those four are the only four in the department. ...if you go into academia as a female professor it's almost suspected that if you would do some sort of like mentoring because there are so few of them and you are trying to increase the number and you always end up getting put into that position where you need to lead this discussion 


\section{Work/Personal Life Balance}

\section{Lynn}

My professional life is my life

Well it turned out that I didn't have kids and my husband is also a professor in this university so there's no balance. My professional life is my life, I mean I spend a lot of time on my professional life. I am always reading, I am always improving my classes, I am always working on assessments and ... issues and community work

\section{Ruth}

People who really have these obligations are those who have children or parents to take care of.

\section{Becky}

I completely failed...

I had no personal life

Last semester, I completely failed...I had no personal life ...I was here every weekend Saturday and Sunday teaching, grading, working on committee work ... I had no life and if it wasn't for sabbatical this semester hmm...I'd still have no life

\section{Sandra}

I have a pretty good

balance this year

I have a pretty good balance this year...got a schedule that I'm mostly done with my homework by Friday night so I have the weekends pretty free other than broomball and pep band but those I consider to be fun so it's ok to me.

\section{Tory}

Sometimes you have to make

sure you don't overwork yourself

When we are together we are like ok let's not check our emails, you know not read anything we are spending like this amount of time together. That's what I mean it's hard because sometimes you have to make sure you don't overwork yourself. 


\section{Unequal Pay}

\section{Becky}

They are getting

our money

Well right but the problem becomes that they have reached those significant positions like full professor and now they are not even trying and they are getting our money (whispers) they are getting huge salaries...uhmmm more than me...so

\section{Male Resistance to Female Authority}

\section{Ruth}

Who are you to be my boss?

Well things like...you know...all of a sudden you are the...the...supervisor or manager or leader over uhmm male engineers who have been working in the field $20 y r$ longer than I have and so they look at you like "who are you to be my boss?" you know so uhmm.. so think a man could step much more easily into that kind of role, I think it was more challenging for me to prove myself capable of being in that role. So it took more time, it took more effort uhm...to win their respect whereas I think at least in my experience if they were to put a man in that role, they just kind of by default are given that respect. So I think women have to work harder to gain respect of their colleagues.

\section{Fifth Wheel}

\section{Becky}

Sometimes I feel like I am

just invited like as a fifth wheel

I agree with the day about nailing the jello to the wall... I was like what? I don't even know what that means... what are you three talking about the jello to the wall, I have not a clue and here we are all supposed to be working on this workshop and just uh..I dunno... it's like they are all in a different world and sometimes I feel like I am just invited like as a fifth wheel and you know... I wrote the book. There's one other fellow that's involved in the project emailed like forty people in our field... and he said I'm getting together and... We are gonna do...uhh...We are gonna add photos to the level of fish key..I emailed back and I said that's great well I'm up for 
photos but what if you picked up the phone and just called me and said you'd like to do this because it is my name on that thing and yet there's... I dunno it always strikes me that when it comes to men they are very sure to acknowledge each other and yet when if there's a woman around it's like...ohh....we'd just take that and use it... and like hellooo... I emailed all of them and said "excuse me I'm not dead yet...could you be a little respectful? So... it's frustrating...

If I team teach with a male and

if that male was at all charismatic...I'm invisible

Well here's another thing I have seen after years of being in classrooms and especially if I team teach with a male and if that male was at all charismatic ...uhmm... the women in the class ...I'm invisible and I don't teach with one of these people anymore because I feel so awful all the time.. I think it happens every single time and it's like ... and I don't know how to...how to approach that

\section{Sandra}

It's kind of hard to make them

realize that you worth it

It's kind of hard to make them realize that you worth it you know what I mean like they look through that... but you kind of have to bring in something to the table and I think that's definitely challenging when you're the only one against up with men so...

\section{Female Student's unique perception of Institutional 'Headwinds'}

\section{Ella}

Most schools make it pretty easy for women to get into STEM programs these days

\section{Sandra}

I do not think there is much discrimination or anything like that here. It's the girls really uncomfortable with it...I do not think it is set up tough for women

\section{Janice}

I had a couple hard professors but you know that's just because usually that's because just it's a hard class but I never, not gotten along with my professors always like -ask them questions and are willing to work with you usually

\section{Tory}

The problem is with the older generation. 